\title{
Coping Strategies and Psychological Maladjustment/ Adjustment: A Meta-Analytic Approach with Children and Adolescents Exposed to Natural Disasters
}

\author{
Daniela Raccanello ${ }^{1}$ (D) Emmanuela Rocca ${ }^{1}$ (D) . Veronica Barnaba ${ }^{1}$ (D) . \\ Giada Vicentini $^{1}$ (D) Rob Hall ${ }^{2} \cdot$ Margherita Brondino $^{1}$ (D)
}

Accepted: 19 January 2022 / Published online: 20 February 2022

(c) The Author(s) 2022

\begin{abstract}
Background Following disasters, children and adolescents can use coping strategies to feel better. A growing body of studies investigated the relation between them and maladjustment/adjustment, i.e., negative symptomatology/positive indicators of development. Yet, these constructs are studied separately.

Objective We conducted two meta-analyses to examine the mean correlation between disaster-related coping strategies and indicators of maladjustment/adjustment following natural disasters in children and adolescents, considering the role of some moderators.

Methods We used PsycINFO, PubMed, Eric, and Scopus databases to identify articles on natural disasters (filters: participants $\leq 18$ years at the disaster, peer-review, English language). Inclusion required investigating the relation between at least one coping strategy and at least one indicator of maladjustment (e.g., post-traumatic stress disorder, depression) and/or adjustment (e.g., self-efficacy, emotion understanding), for a total of 26 studies ( $k=64, n=9692$, for maladjustment; $k=37, n=3504$, for adjustment).

Results There were global positive significant correlations between coping strategies and negative symptomatology $\left(r_{\text {pooled }}=.23\right)$ for maladjustment, and positive indicators $\left(r_{\text {pooled }}=.17\right)$ for adjustment. Negative symptomatology positively correlated with escape $(r=.19)$, social isolation $(r=.15)$, submission $(r=.64)$, and opposition $(r=.16)$; positive indicators positively correlated with problem solving $(r=.31)$, social support $(r=.22)$, and submission $(r=.30)$. We found a moderating role of age, disaster type, and continent for maladjustment.
\end{abstract}

Conclusions The study presented an analysis of the coping strategies that can be effective for children and adolescents dealing with natural disasters.

Keywords Coping strategies $\cdot$ Maladjustment $\cdot$ Adjustment $\cdot$ Natural disasters $\cdot$ Children and adolescents $\cdot$ Meta-analysis

This article is based on two conference posters (Brondino et al., 2019; Raccanello et al., 2019a). We received funding from Fondazione Cariverona, Bando Ricerca Scientifica 2017.

Margherita Brondino

margherita.brondino@univr.it

Extended author information available on the last page of the article 


\section{Introduction}

Natural disasters such as earthquakes, floods, or fires seem to be occurring at an increasing rate, sometimes leading to catastrophic situations that suddenly disrupt everyday life, resulting in great damage and destruction (Assar, 1971; EM-DAT, n.d.; Fergusson \& Boden, 2014). They can cause great suffering, destroying people's physical, biological, and social environment, with short and long-term consequences for their health and wellbeing (World Health Organization, n.d.). Their impact is particularly relevant for children and adolescents, given their vulnerability related to their cognitive and emotional level of development (Kar, 2009; Masten \& Osofsky, 2010). Little is known about the efficacy of coping strategies when dealing with the traumatic consequences of disasters; nevertheless, this knowledge is a necessary step in identifying strategies for preparing children and adolescents to face possible future disasters. Therefore, we examined the literature on natural disasters focusing on the relation between coping strategies and psychological maladjustment/adjustment in children and adolescents using a meta-analytic approach.

\section{Impact of Natural Disasters on Children and Adolescents}

Many studies on the effects of being exposed to large-scale traumatic events document the impact of these events on psychological maladjustment; however, some studies also point to the existence of increased resilience through adjustment (for examples of measures on psychological maladjustment/adjustment see Cheng et al., 2014).

The exposure to natural disasters can lead to serious negative short and long-term effects for children and adolescents (Fergusson \& Boden, 2014; Furr et al., 2010; Kar, 2009; Masten \& Osofsky, 2010; Neria et al., 2008; Tang et al., 2014; Wang et al., 2013; Weissbecker et al., 2008). Compared to adults, children and adolescents' vulnerability to the deleterious effects of disasters is due to the fact that they are less well equipped with adaptive coping strategies and abilities to control emotions such as anxiety (Norris et al., 2002; Weems et al., 2015). Maladjustment includes traumatic consequences for mental health, with increased rates of psychopathology such as post-traumatic stress disorder (PTSD), depression, anxiety and fear, and psycho-social distress, usually with a peak of symptoms or effects in the first year after the disaster.

A meta-analysis including more than 74,000 children and adolescents who were victims of natural or technological disasters indicated that the magnitude of the association between disasters and PTSD, ranging from small to medium, varied according to factors such as the characteristics of the children (e.g., gender) or the characteristics of the exposure (e.g., disaster type; Furr et al., 2010). However, data on the prevalence and the severity of symptoms are inconsistent, with decreasing, increasing, or stable levels over time (Kar, 2009). For example, Kar (2009) reported that the prevalence of PTSD varied between 5 and $43 \%$, while a meta-analysis involving more than 42,000 participants indicated variations between 1 and 95\% (Wang et al., 2013). Also figures on the prevalence of depression vary widely, ranging for example from 1.6 to $81 \%$ (Wang et al., 2013), from 7.5 to $45 \%$ (in a meta-analysis with more than 12,000 children, Tang et al., 2014), or from 2 to $69 \%$ (in another meta-analysis with four-to-17-year-olds, Lai et al., 2014). A variety of risk factors for depression have been investigated. These include age (with inconsistent findings about the expected higher prevalence amongst older compared to younger children), trauma characteristics such as being entrapped or witnessing injuries or deaths during the disaster, and post-trauma characteristics such as the absence of social support (Lai et al., 2014; 
Tang et al., 2014). Bonanno et al. (2010) reported that exposure to disasters can increase the probability of experiencing anxiety disorders, although published meta-analyses such as that by Wang et al. (2013) found relatively few studies that explored this relationship. Finally, psycho-social distress can follow a disaster, as found for example amongst children and adolescents who were victims of hurricanes or earthquakes (Vigil \& Geary, 2008; Vigna et al., 2010; Yang et al., 2010).

Even if maladjustment is quite common in children and adolescents who experienced a disaster (Flynn \& Norwood, 2004), some studies indicated that exposure could in some cases represent a positive "turning point experience" (Rutter, 1996) and that post-disaster sequelae could include psychological adjustment. Adjustment can be assessed through a variety of measures (Cheng et al., 2014) pertaining to cognitive, emotional, social, or motivational domains. Notwithstanding that psychological distress may impact children and adolescents' cognitive and emotional functioning, some studies report that using particular coping strategies after disasters such as earthquakes is associated with increases in cognitive performances (Cadamuro et al., 2015). In addition, one study showed that two years after an earthquake there were no differences in emotion regulation and understanding between children who had been victims of the disaster and a control group (Raccanello et al., 2017). Concerning the social domain, a few studies reported positive effects of exposure to natural disasters, such as a better understanding of themselves and others (Yang et al., 2010), the growth of communication and relationship skills (Bokszczanin, 2012), as well as attention, care, and altruism (Benenson et al., 2007). Other studies reported that post-traumatic stress symptoms were positively associated with intention to contact and help other survivors (Vezzali et al., 2016). Li et al. (2013) found that age impacted the tendency to be altruistic after witnessing disruption due to a major earthquake: While nineyear-olds increased altruistic giving, six-year-olds became more selfish. However, these differences vanished after three years. Regarding the motivational domain, some studies on the effects of hurricanes and earthquakes reported that perceived competence, self-efficacy, or self-concept can play a key role for post-disaster adjustment (Cryder et al., 2006; Kilmer \& Gil-Rivas, 2010; Wu et al., 2014; Yang et al., 2010). Finally, some authors reported that child victims of tornados were more or less resilient in the face of adversity, with variations in recovery depending on the presence of protective factors such as self-regulation or returning to school (Vezzali et al., 2016). Overall, increases in resilience and adjustment reflect effective coping and adaptation in the face of major life stress (Masten \& Osofsky, 2010).

\section{Risk and Protective Factors}

Research findings indicate that children and adolescents' reactions and susceptibility to natural disasters can vary in response to a large number of factors, related to biological, psychological, and contextual dimensions (Masten \& Osofsky, 2010; Weems, 2015). This variability is reflected in the various estimates reported in the data on the prevalence of post-traumatic reactions and by the fact that notwithstanding having experienced a trauma, a percentage of children and adolescents develop resilience (Kilmer \& Gil-Rivas, 2010; La Greca et al., 2002).

First, findings concerning age differences are not consistent for reactions such as antisocial and aggressive behaviors or PTSD (Celebi Oncu \& Metindogan Wise, 2010; Vezzali et al., 2016). The different levels of vulnerability between children and adolescents could be related to different risk and protective factors (Masten et al., 1990). Younger children 
are frequently protected by a lower exposure to disaster, especially when caregivers and people supporting them remain stable (Osofsky, 2004; Silverman \& La Greca, 2002). Adolescents are more exposed both to disaster-related information and to risks given their higher involvement within the society, but at the same time they have more resources, such as problem solving skills, social support outside the family, or survival skills to cope with negative events (Masten \& Osofsky, 2010).

Second, natural disasters differ in characteristics such as causes, frequency, controllability, rapidity of onset, duration of the alarm and emergency phases, extension of the area of impact, disruptive potential, duration of the following risk, and probability of reoccurrence of the event (Cuzzolaro \& Frighi, 1991). Therefore, it is plausible that these aspects can impact psychological functioning in different ways. Specifically, some studies indicated that the consequences of human-induced compared to natural disasters are more likely to persist over time (Green et al., 1992). Another study found that the type of disaster (e.g., natural, technological) is a weaker predictor of children's PTSD compared to the extent of their exposure to the disaster (Celebi Oncu \& Metindogan Wise, 2010).

It is worth noting that some studies examined the role of the time elapsed since a disaster (e.g., Wang et al., 2013). While traumatic and negative reactions are typically more intense in the first year after a disaster, they do not always decrease over the long-term (Celebi Oncu \& Metindogan Wise, 2010; Gökçen et al., 2013; Kar, 2009; La Greca et al., 1996; Raccanello et al., 2017). Data on adults indicate that adjustment measured, for example, in terms of optimism did not vary after several months (Prati \& Pietrantoni, 2009).

\section{Coping Strategies}

Following disasters, children and adolescents can use a large variety of coping strategies to feel better. Coping is a multi-component construct referring to all the ways employed to face stressful events (Skinner et al., 2003). In the literature, different classifications of coping strategies have been proposed. Among them, the pioneering work of Lazarus and Folkman (1984) distinguished between problem and emotion-focused strategies; the first oriented to find a solution to the problematic event that caused the negative emotions, and the second to alleviate the distress caused by it. Schaefer and Moos (1992) differentiated active and avoidant coping, focused respectively on actions to approach the problem with processes of cognitive reconstruction, elaboration, and support seeking on the one hand, and ways to escape from the problem, feeling helpless, and trying to obtain alternative rewards on the other hand. Attempting to produce a broad classification of coping strategies, taking into account age changes, Zimmer-Gembeck and Skinner (2011) proposed a developmental classification in which they code strategies into three categories corresponding to different adaptive functions, focused on competence, relatedness, and autonomy (Deci \& Ryan, 1985). Each category included two connected families of strategies and their opposites. The first set, focused on competence, involves problem solving and information seeking in contrast to helplessness and escape. These strategies help individuals to adapt their behaviors to the environmental constraints they face. The second set, focused on relatedness, comprises self-reliance and social support in contrast to delegation and social isolation. It revolves around endeavors to build reliance amongst and between people caught up in the situation. The third set, focused on autonomy, includes accommodation and negotiation in contrast to submission and opposition. These strategies are organized around efforts to "trade" options to reach one's own goals. 
Some meta-analyses have investigated the effects of using different coping strategies on stressful events. For example, passive coping strategies such as avoidance, social isolation, and rumination, have been found to have negative effects on the psychological adjustment to stressful events (Cofini et al., 2015). A meta-analysis focused on the violence that women suffer from their partners revealed that escape as a type of strategy, seems to facilitate the maintenance of the disorder, and is positively related to PTSD symptoms. On the other hand, Clarke (2006) explored the relation between active coping and psychosocial health among youth and confirmed that active coping strategies such as problem solving, assertive communication, and seeking social support are linked to healthy adjustment (Compas et al., 2001; Fields \& Prinz, 1997; Grych \& Fincham, 1997). However, it is worth noting that the adaptivity of different coping strategies depends on the characteristics of the individuals and of the context.

Concerning disasters, a growing body of studies is exploring the relation between coping strategies and children's maladjustment/adjustment. These various studies investigated coping types such as problem-focused vs. emotion-focused coping, active vs. avoidance coping. Some studies focused on the relation between coping strategies and negative symptomatology such as PTSD, depression, and anxiety after exposure to a natural disaster (e.g., Papadatou et al., 2012; Terranova et al., 2009; Vigil \& Geary, 2008). For example, Tang et al. (2014) conducted a meta-analysis on risk factors for depression in children and adults who survived natural disasters, observing that the most significant predictors for children were having experienced previous trauma, being trapped or injured during the disaster, having witnessed injury or death during the disaster, and not receiving social support. Findings from Weems and Graham (2014) indicated that, in the context of hurricanes, more resilient children-characterized by low post-traumatic stress symptoms and high exposure- have lower levels of avoidance coping compared to the others. Some studies revealed an association between coping strategies and adjustment in terms of resilience, self-concept, and selfefficacy (e.g., Bokszczanin, 2012; Stratta et al., 2013; Wang \& Gan, 2011). A meta-analysis by Prati and Pietrantoni (2009) investigated the relation between some coping strategies and indicators of adjustment such as the post-traumatic growth (PTG) in adults. The results showed that strategies such as optimism and social support are positively related to PTG.

In summary, the psychological literature suggests that different coping strategies can vary in their efficacy from case to case when applied in natural disasters. However, the role of coping strategies as risk or protective factors in relation to disasters has not yet been examined systematically. It is worth noting that most of the interventions examined in the psychological literature were conducted after a disaster has occurred (for meta-analyses on their efficacy see Brown et al., 2017; Kar et al., 2009; Pfefferbaum et al., 2019). However, disaster preparedness and prevention are of key relevance to support adjustment and use of effective coping strategies in the case of an emergency (for example of one intervention conducted before disasters, see Raccanello, et al., 2019b, 2020a, 2021; Vicentini et al., 2020).

\section{Current Study and Hypotheses}

Using a meta-analytic approach, we synthesized the body of research on disaster-related coping strategies with children and adolescents. We aimed at assessing the mean correlation between several coping strategies (Table 1; Zimmer-Gembeck \& Skinner, 2011) and maladjustment/adjustment measures, following natural disasters, taking into account the role of some moderating factors. 
In line with previous meta-analyses on the efficacy of coping strategies (Clarke, 2006; Cofini et al., 2015; Compas et al., 2001; Fields \& Prinz, 1997; Grych \& Fincham, 1997), along with studies on the relation between coping strategies and psychological consequences of disasters (Bokszczanin, 2012; Papadatou et al., 2012; Prati \& Pietrantoni, 2009; Stratta et al., 2013; Tang et al., 2014; Terranova et al., 2009; Vigil \& Geary, 2008; Wang \& Gan, 2011), taking into account Zimmer-Gembeck and Skinner's classification (2011), we hypothesized that after natural disasters: (1) children and adolescents' use of strategies such as helplessness, escape, delegation, social isolation, submission, and opposition is related to maladjustment (Hypothesis 1); and (2) children and adolescents' use of problem solving, information seeking, self-reliance, social support (including both seeking and giving), accommodation, and negotiation is related to adjustment (Hypothesis 2). In brief, we examined the efficacy of 12 types of families of coping strategies on measures of maladjustment and adjustment separately by conducting two meta-analyses.

We considered the variety of post-disaster reactions related to maladjustment/adjustment (Celebi Oncu \& Metindogan Wise, 2010; Cuzzolaro \& Frighi, 1991; Gökçen et al., 2013; Green et al., 1992; Kar, 2009; La Greca et al., 1996; Masten \& Osofsky, 2010; Masten et al., 1990; Osofsky, 2004; Prati \& Pietrantoni, 2009; Raccanello et al., 2017; Silverman \& La Greca, 2002; Vezzali et al., 2016). We explored the moderating role of factors such as age (children, adolescents), type of disasters (earthquakes, floods and hurricanes, wildfires), and continent (America, Europe, Asia).

This work is part of a larger project aimed at understanding the links between emotions and coping strategies in children, adolescents, and adults faced with natural and technological disasters (HEMOT® project, Helmet for EMOTions, https://www.hemot.eu; Raccanello et al., 2019b, 2020a, 2020b, 2020c, 2021; Vicentini et al., 2020). Knowing which coping strategies are effective for diminishing maladjustment and increasing adjustment in children and adolescents is of critical relevance for planning interventions to support victims before, during, and after a disaster.

\section{Method}

\section{Literature Search and Search Results}

We searched for journal articles explicitly focused on the effects of the exposure to natural disasters amongst children and adolescents. We conducted the literature search during 2020, using the databases PsycINFO, PubMed, Eric, and Scopus. The search terms were: natural disasters, coping, children or adolescents. We report in the PRISMA diagram (Fig. 1) the results of the search strategies and the selection processes (Moher et al., 2009).

Studies included in the meta-analyses: (a) involved participants 18 years of age or younger who had been exposed to a natural disaster; (b) examined at least one coping strategy used to manage the psychological consequences of the disaster; (c) included the assessment of at least one measure of maladjustment and/or one measure of adjustment; (d) reported sufficient statistical information so that effect sizes could be calculated; (e) analyzed data that were collected after the disaster, between two and 54 months after the exposure; (f) were written in English. 


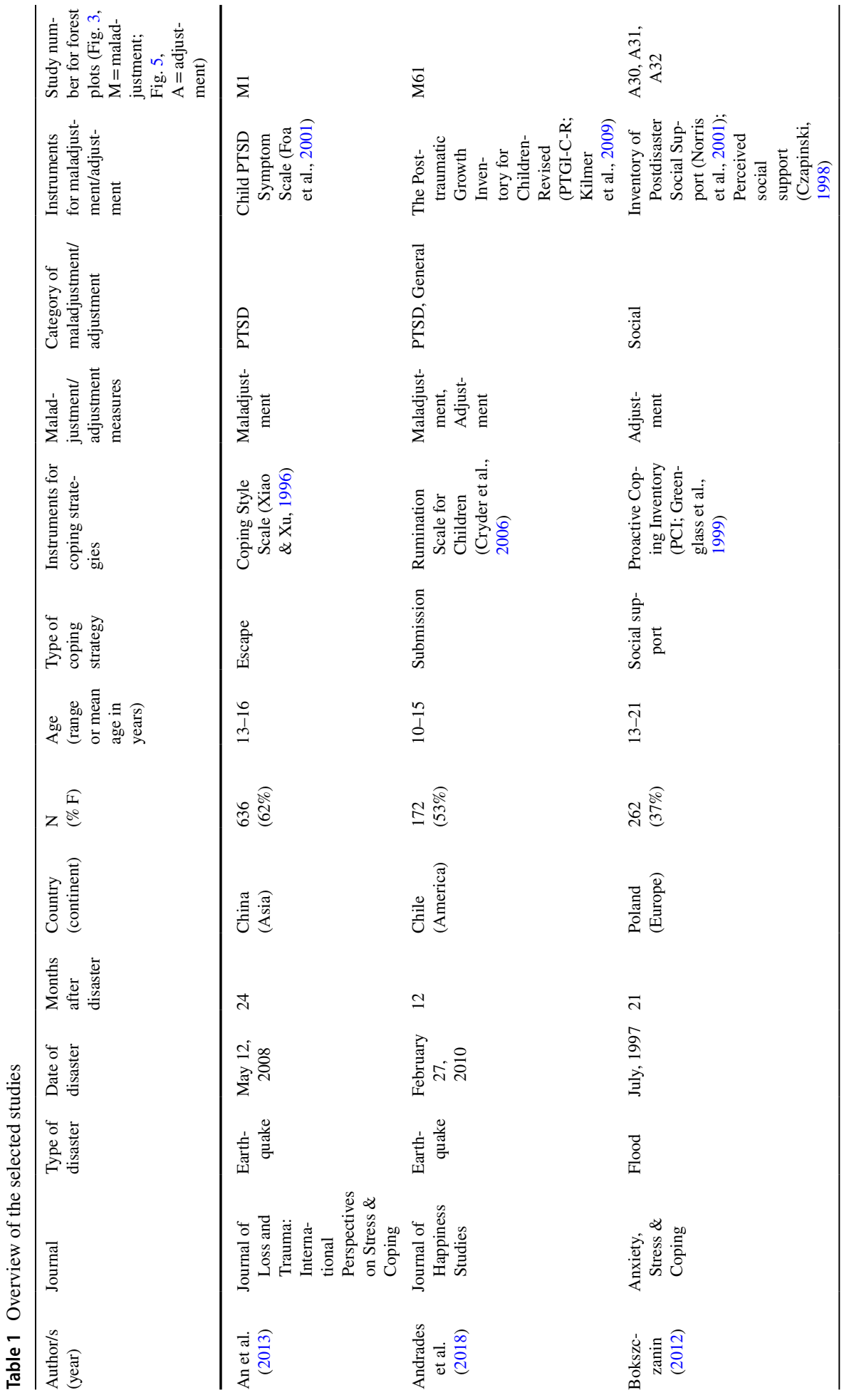




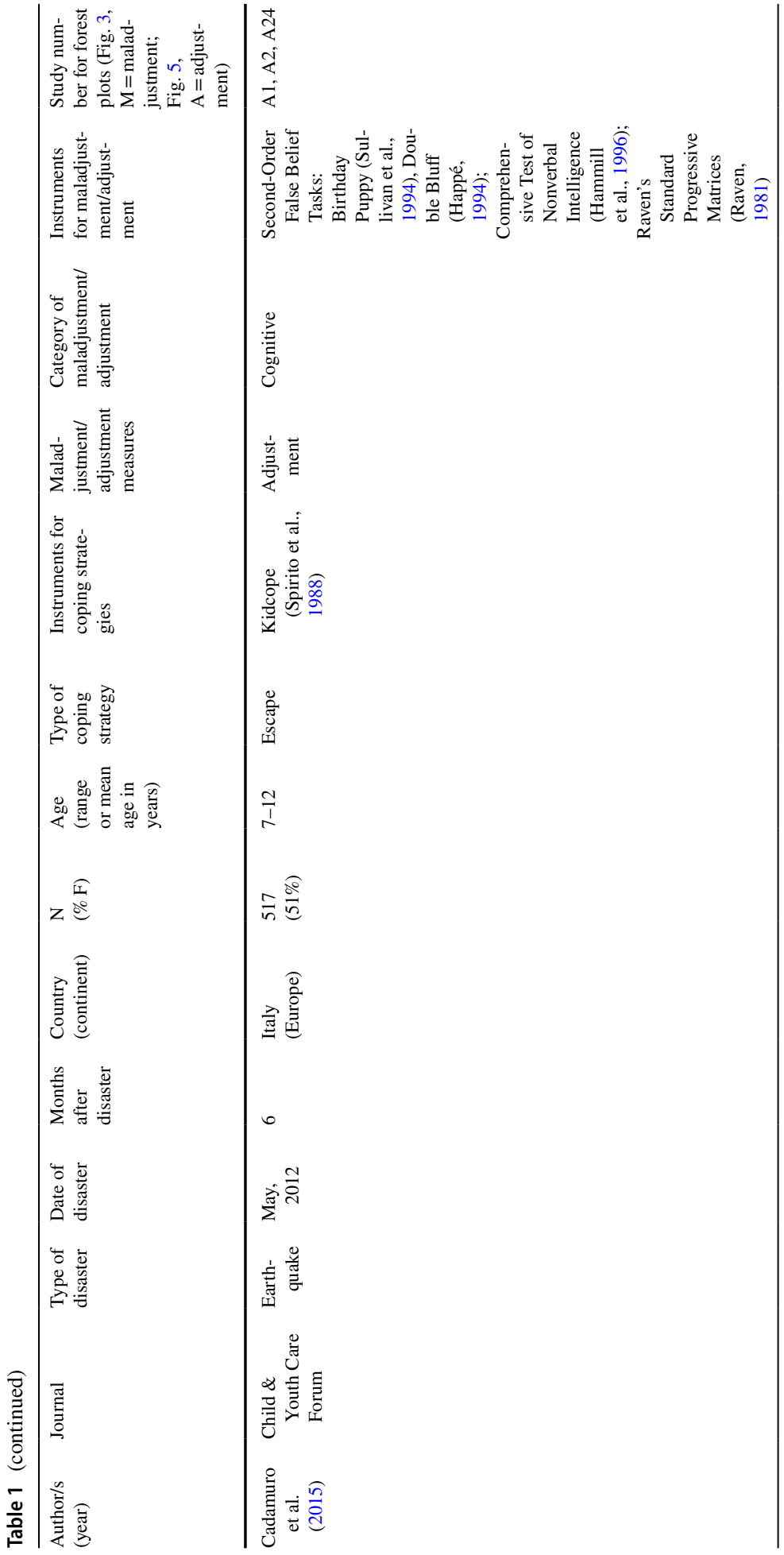




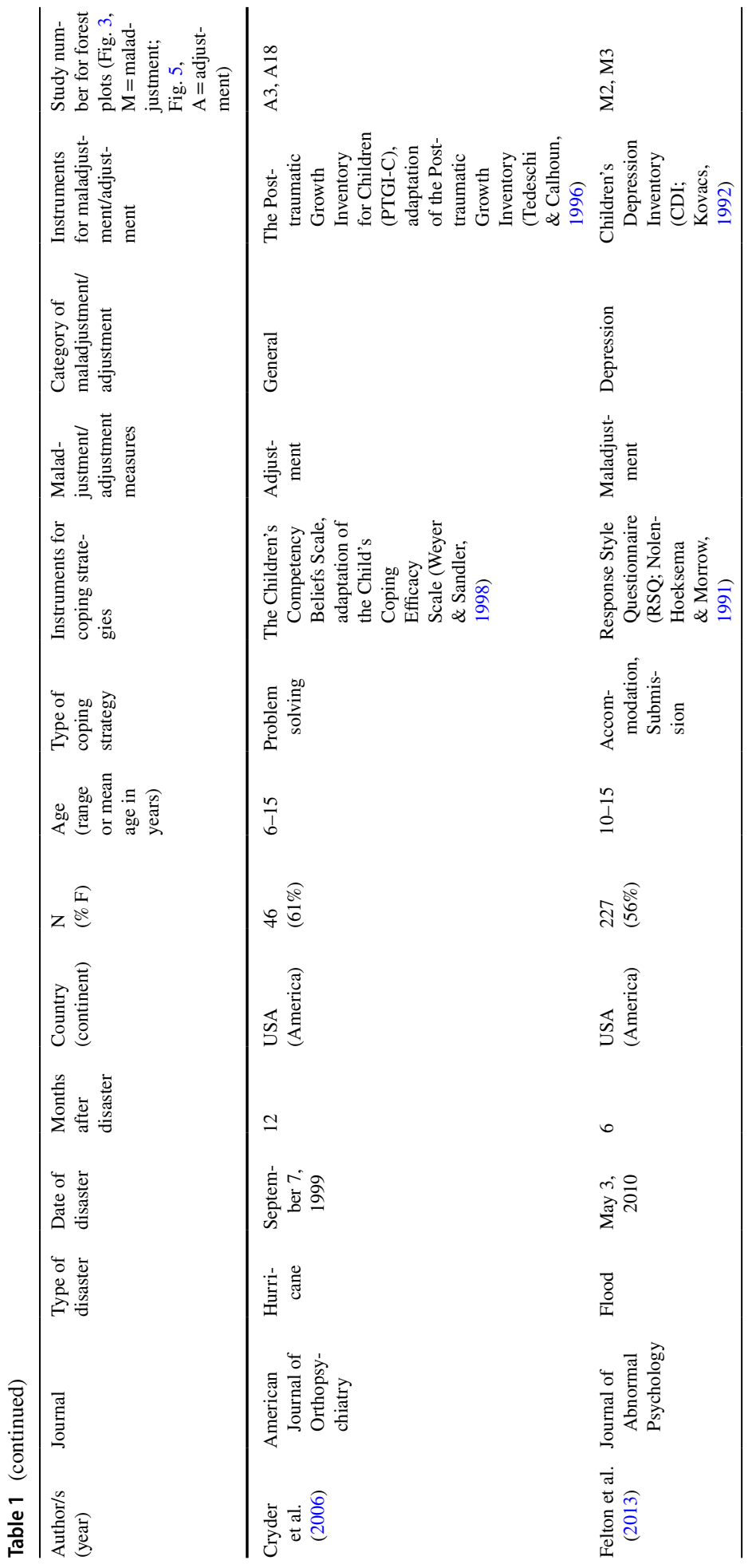




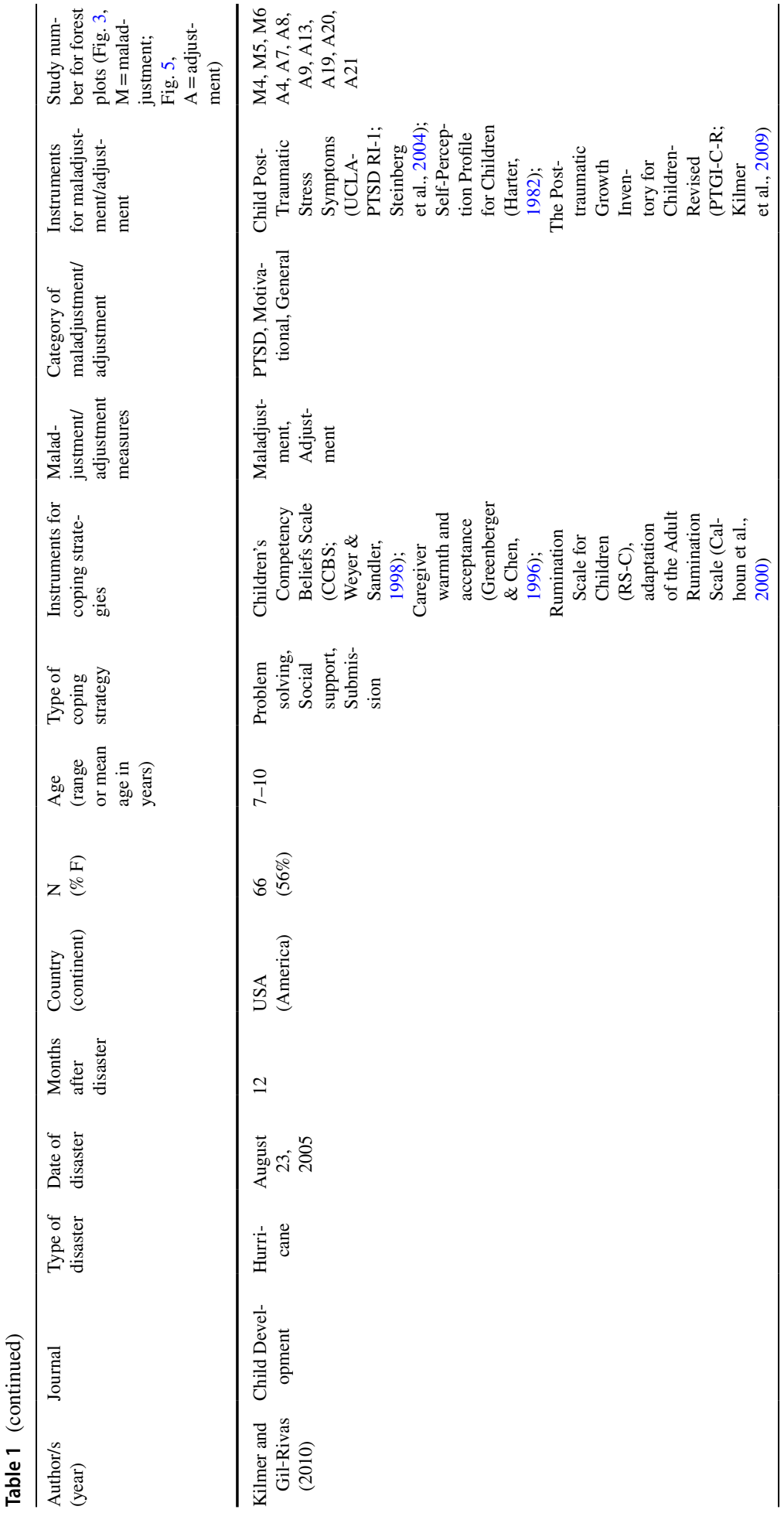




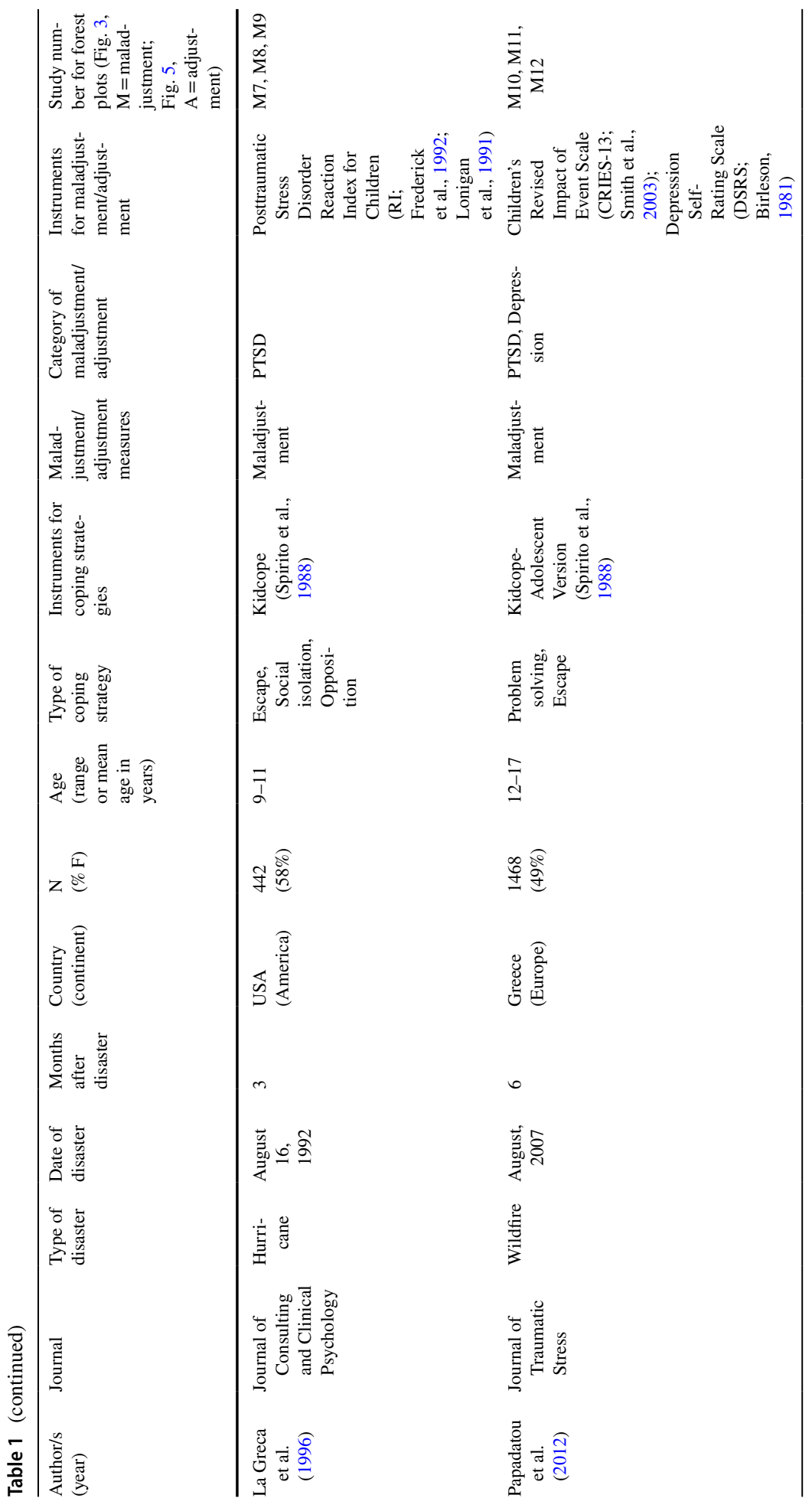




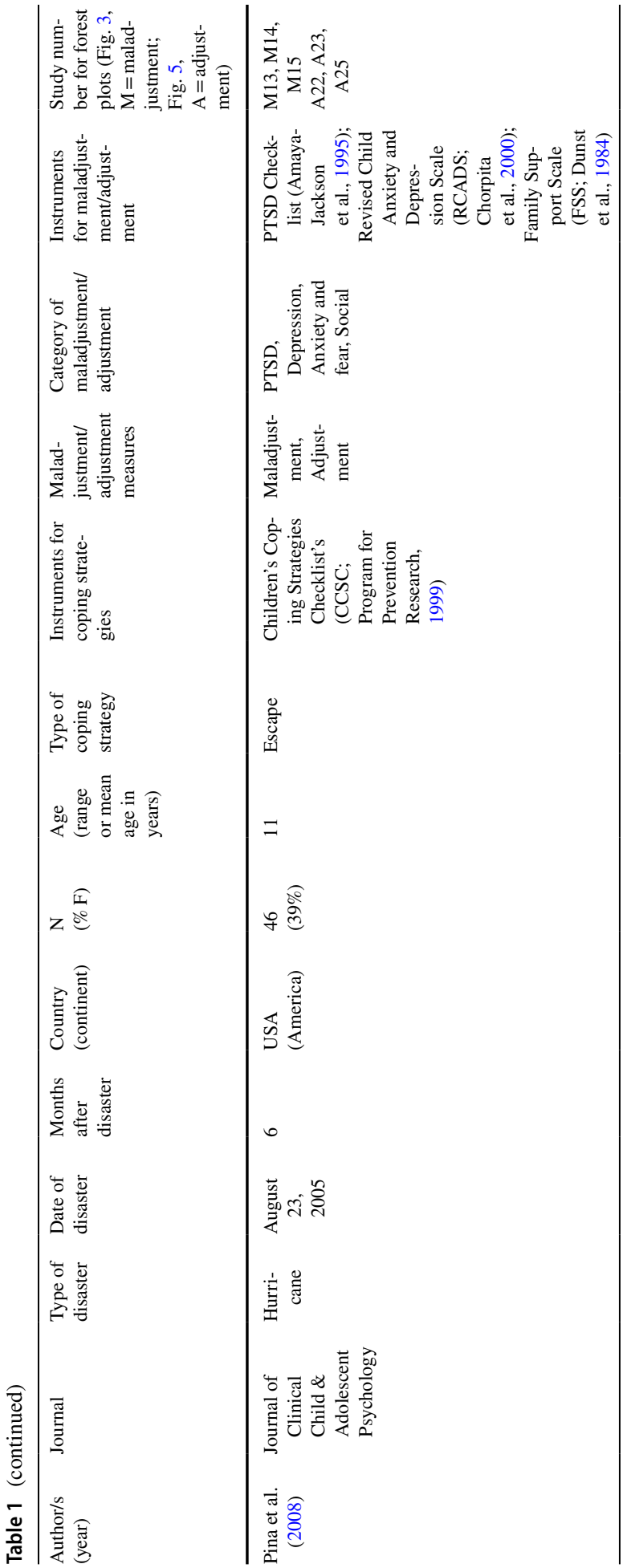




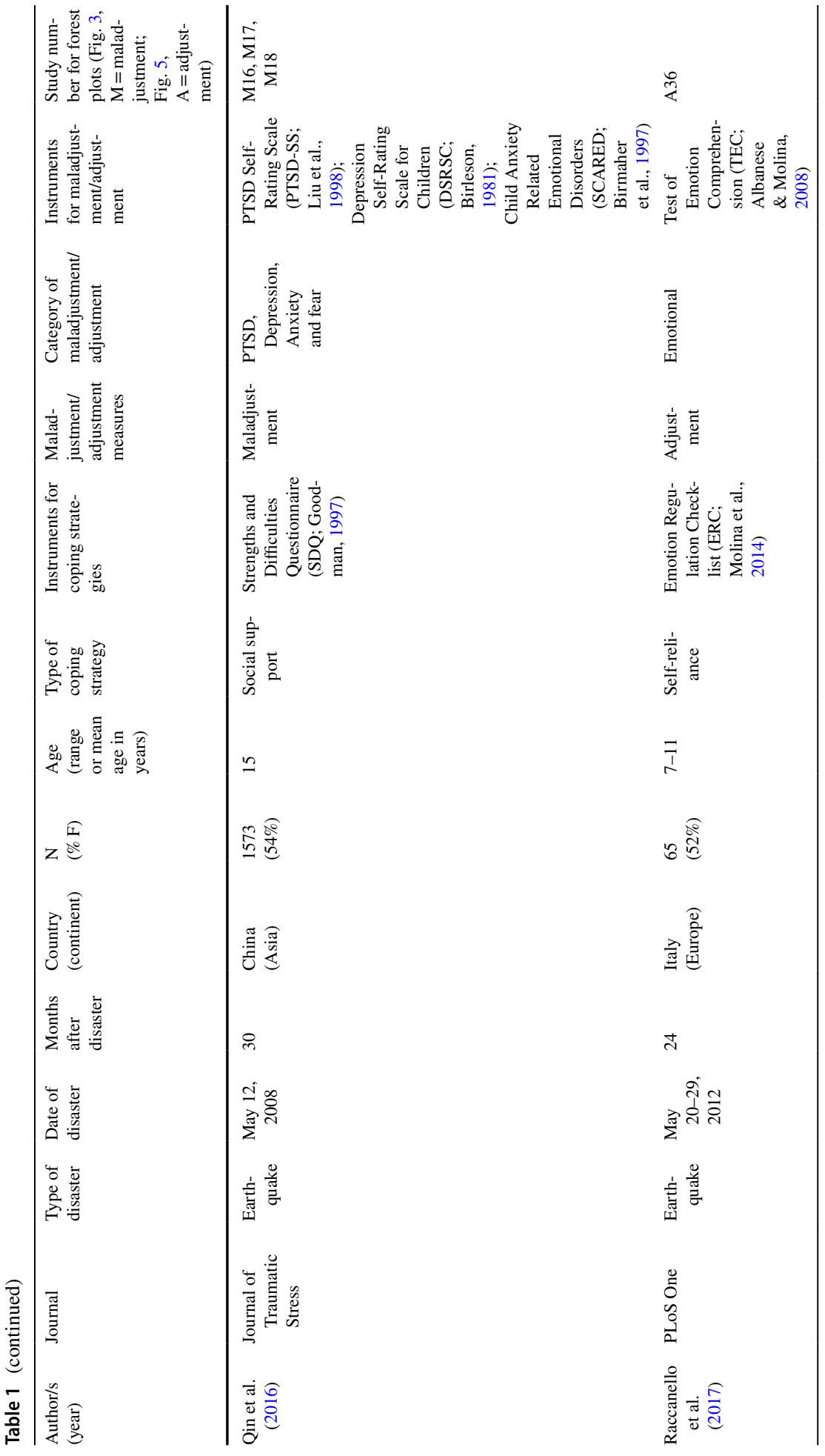




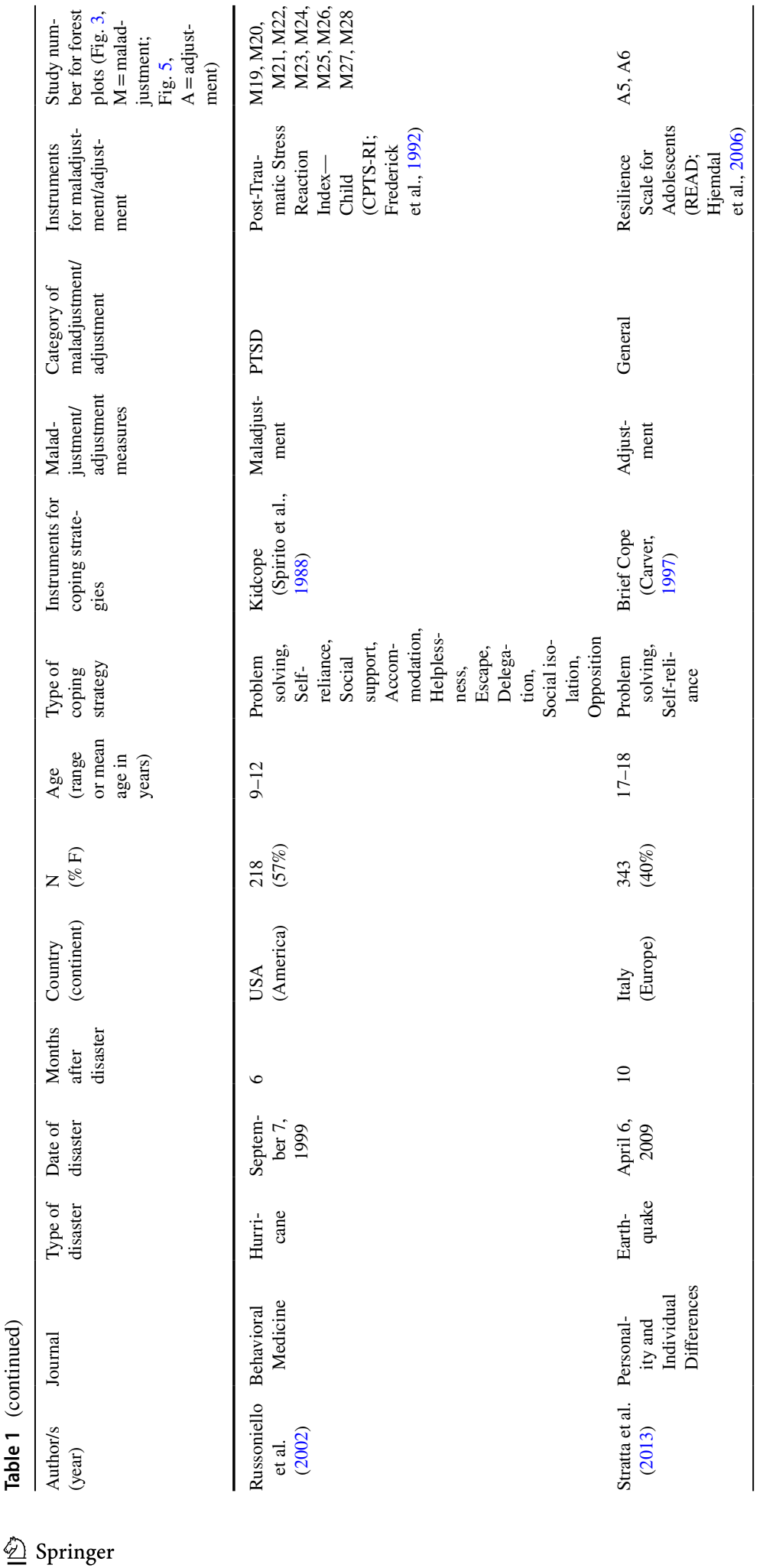




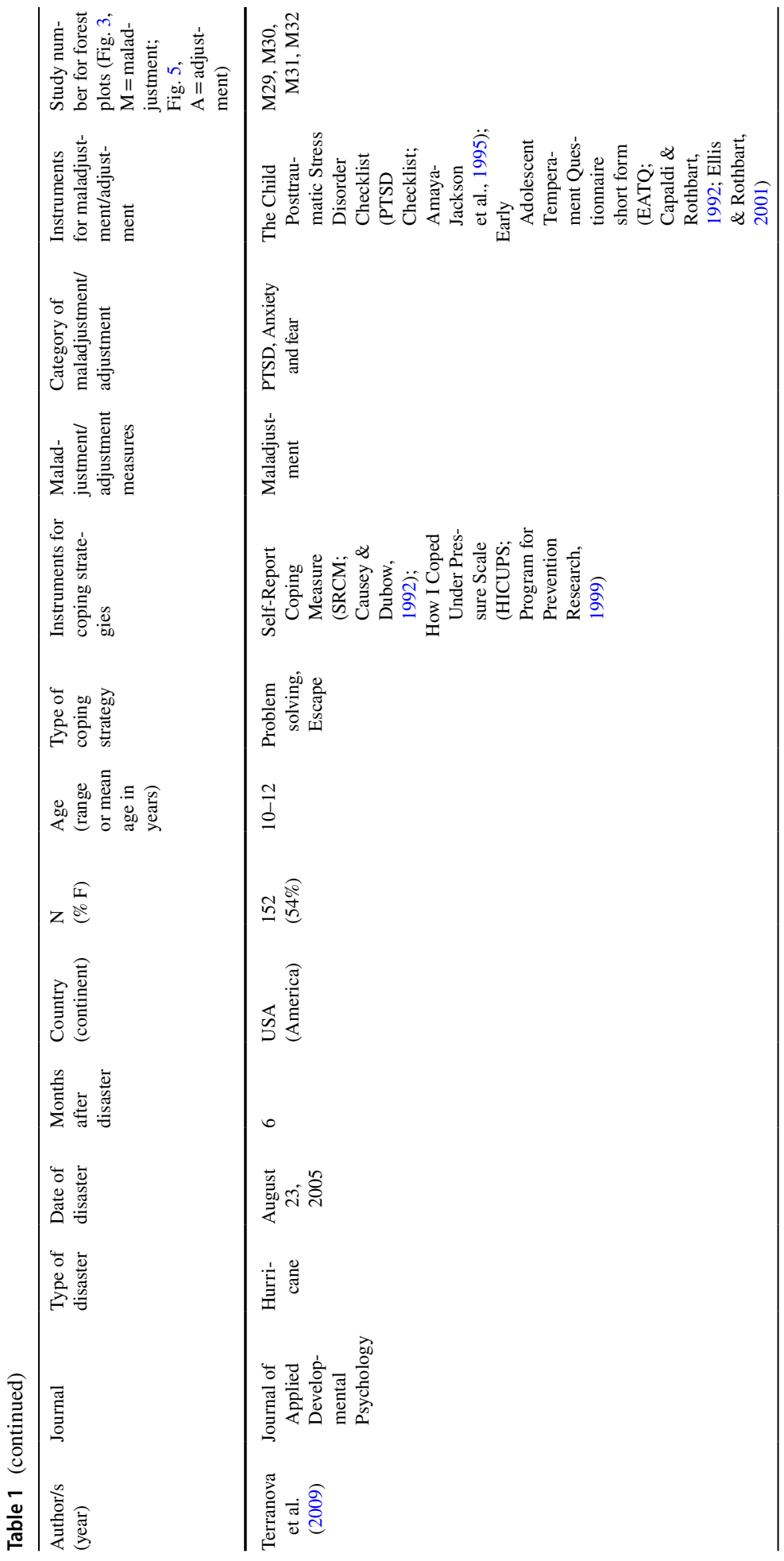




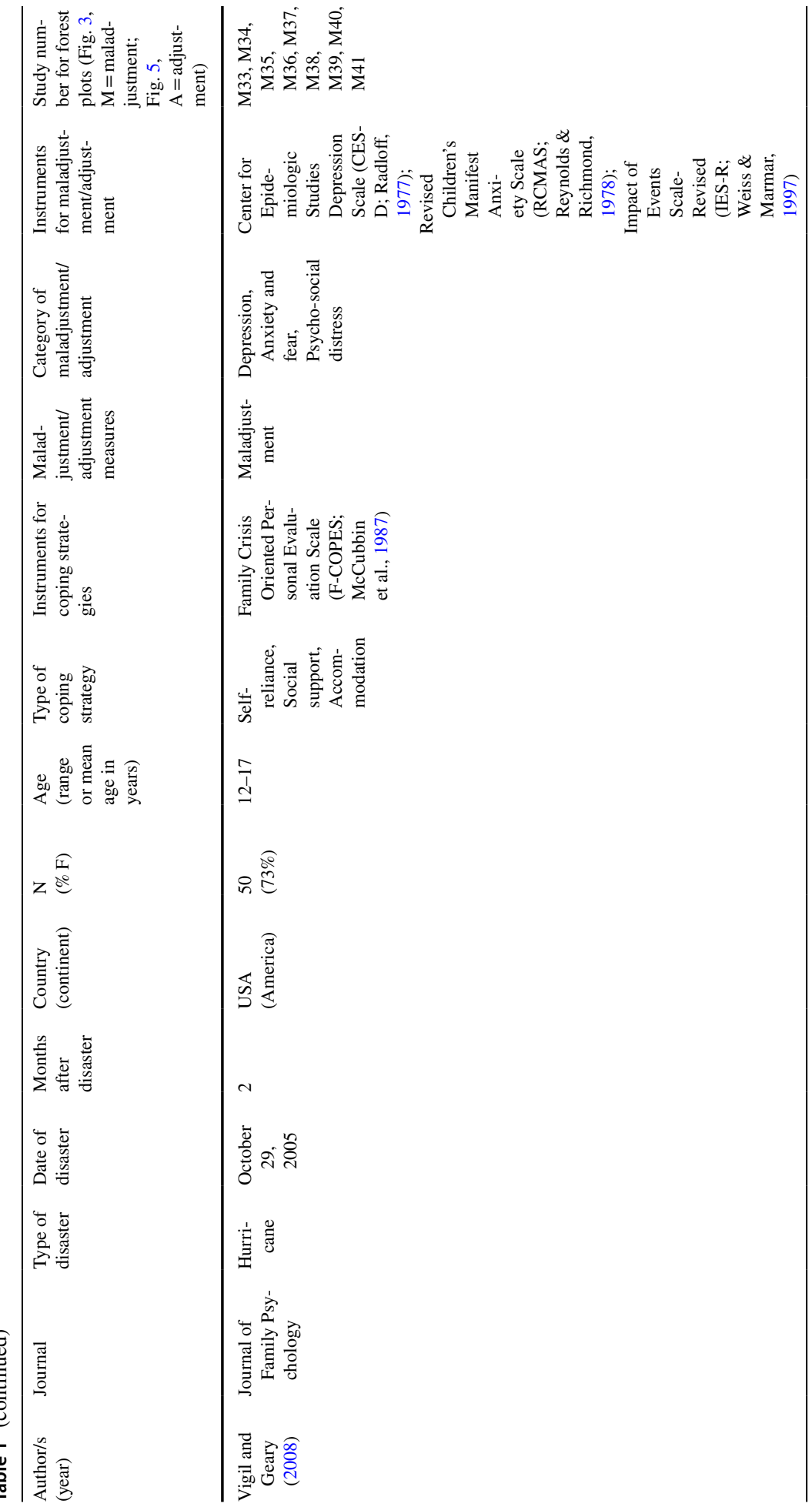




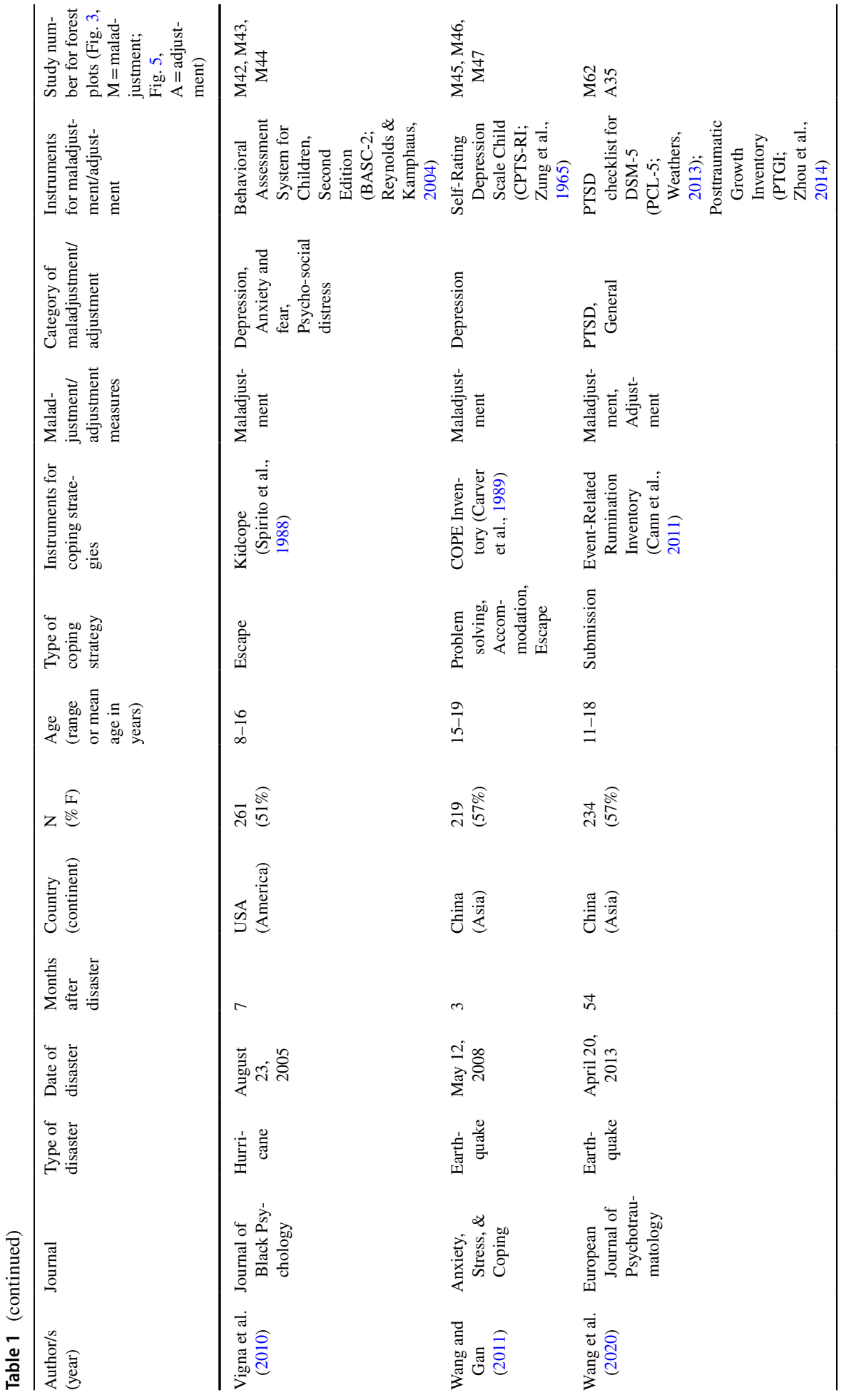




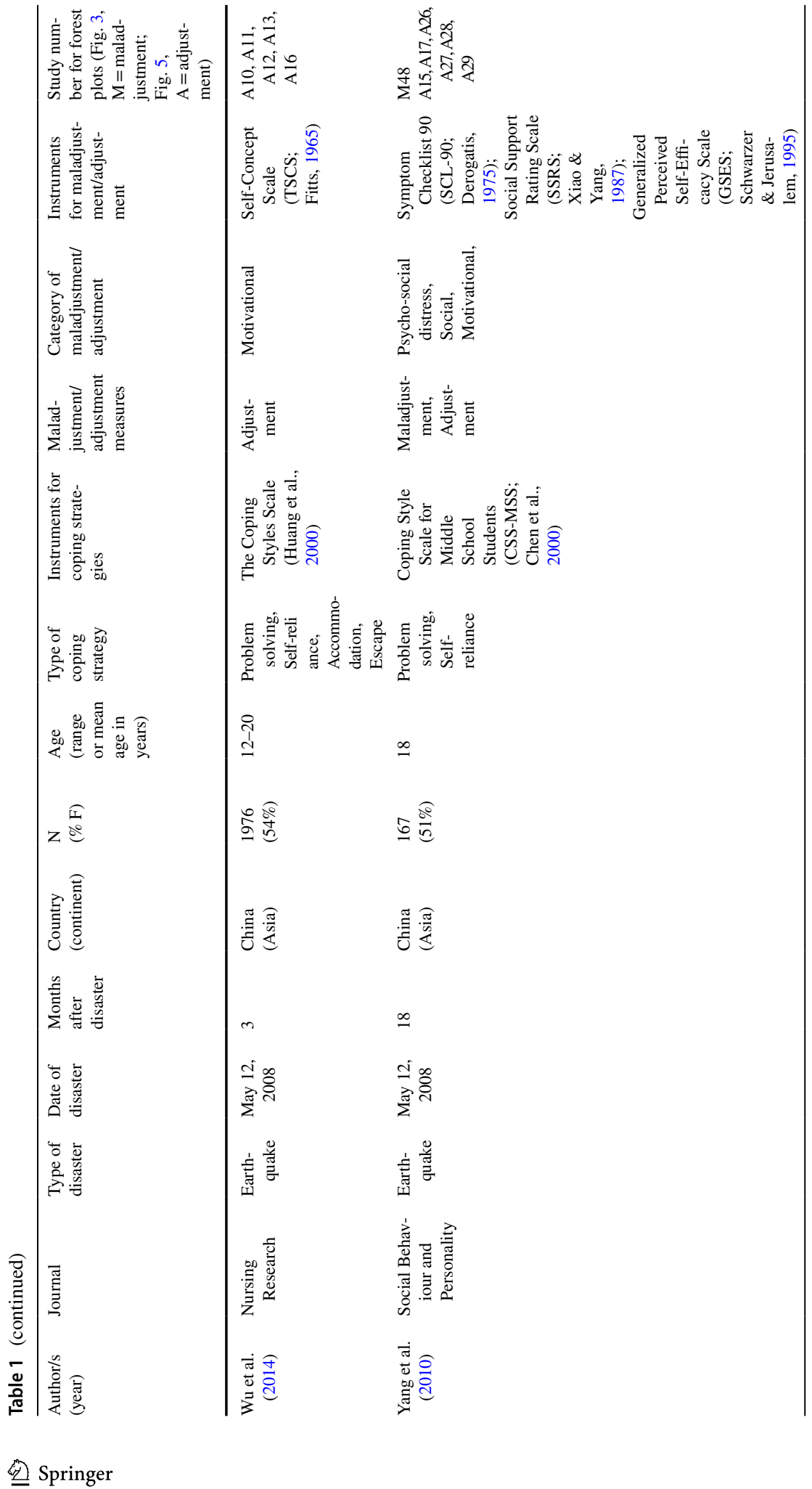




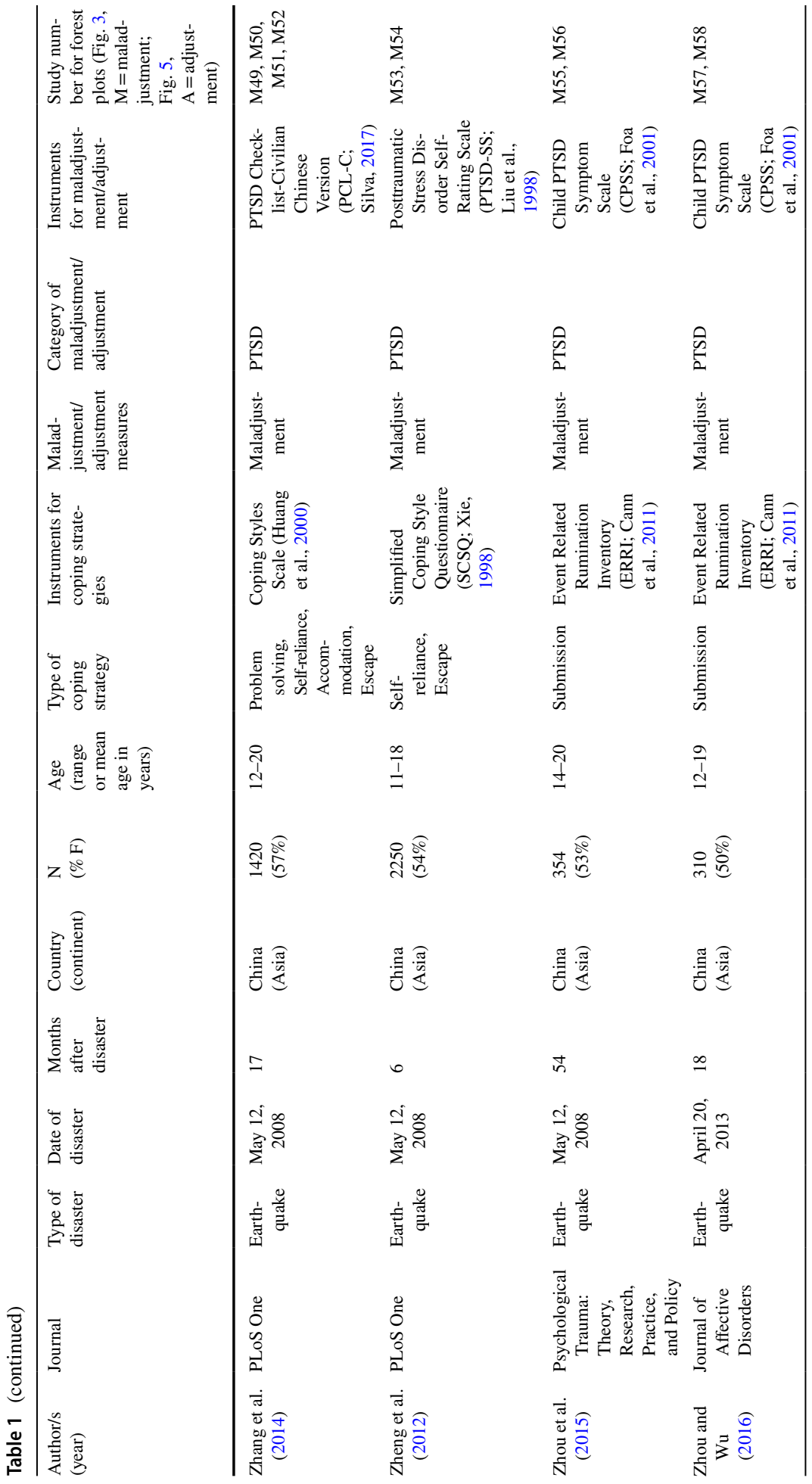




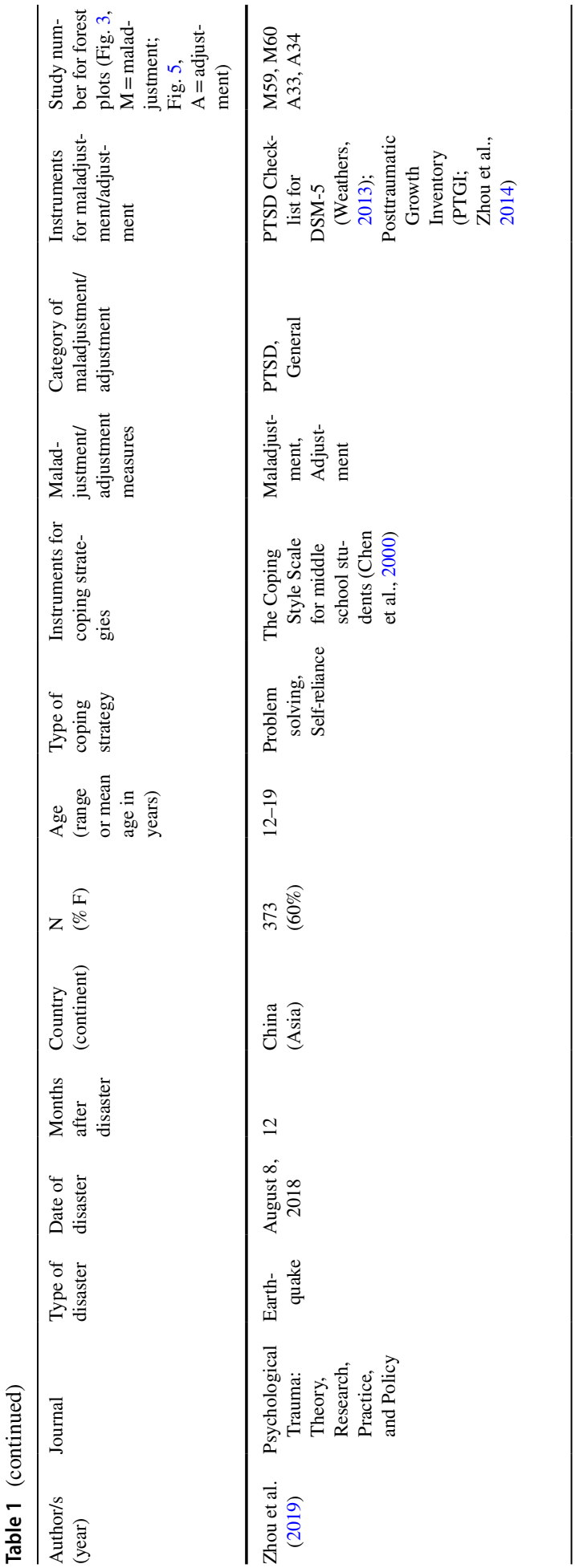




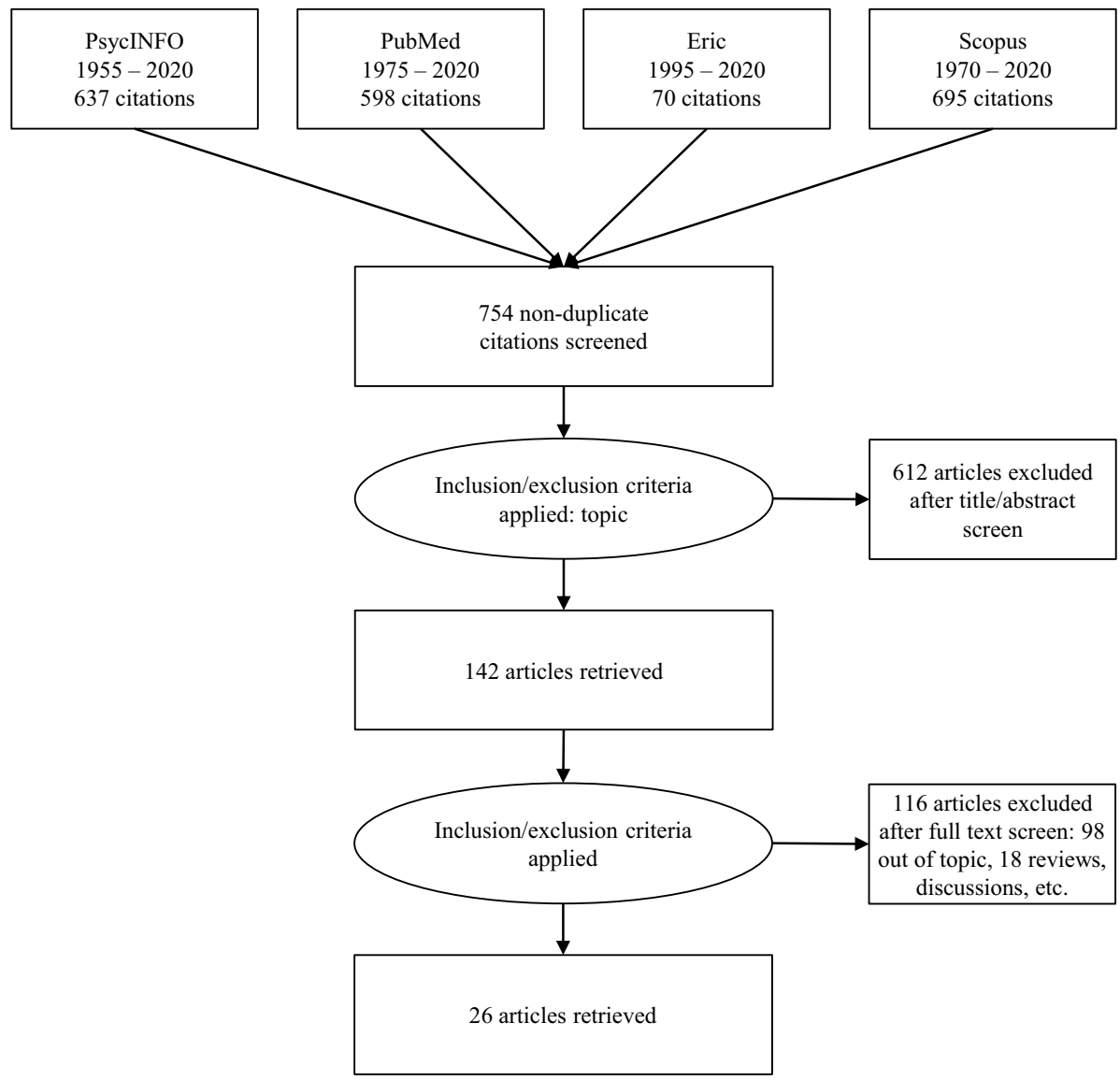

Fig. 1 PRISMA Diagram (Moher et al., 2009)

We excluded publications reporting reviews, discussions, single-case studies, and qualitative studies. In addition, we excluded those studies which did not include the statistical indexes necessary as inputs for a meta-analysis.

As reported in the PRISMA diagram (Fig. 1), the initial search identified a total of 2000 publications. Six hundred and thirty-seven publications were indexed in PsycINFO and had been published between 1955 and 2020; 598 were indexed in PubMed and had been published between 1975 and 2020; 70 were indexed in Eric and had been published between 1995 and 2020; and 695 were indexed in Scopus and had been published between 1970 and 2020. As a first step, we removed 1246 duplicates from this initial set, i.e., the same publications downloaded in different searches. Then, we screened the 754 selected publications. As a second step, we read all the titles and abstracts and included only the publications pertinent in terms of topic-i.e., respecting the inclusion criteria-for a total of 142 . As a third step, we read each article, and that led to us excluding 98 publications because they were off topic, and 18 because they reported reviews, discussions, single-case studies, and qualitative studies. This last step of the selection process was conducted by two 
independent judges; the reliability was $100 \%$. No publications were excluded after the discussion between judges. Thus, the search identified a selection of 26 publications.

For ethical issues, we adhered to the recommendations of the American Psychological Association.

\section{Coding and Reliability}

We reviewed and coded the eligible studies for several variables. First, we coded the type of family of coping strategy, and we identified whether the studies included maladjustment/ adjustment measures. Second, we coded them for other moderating variables, i.e., age group (children: younger than 12 years; adolescents: older than 12 years), type of disaster (earthquakes, floods and hurricanes, wildfires), and continent (America, Europe, Asia). In five studies (Andrades et al., 2018; Cryder et al., 2006; Felton et al., 2013; Pina et al., 2008; Vigna et al., 2010) the data concerning children and adolescents were not separated, so we excluded these studies from the analyses examining the moderating effect of age. Finally, the participants in the studies by Wang et al. (2013) and Zheng et al. (2012) were considered as adolescents even if their age ranged from 11 to 18 years.

For an overview of the included studies, see Table 1.

\section{Type of Coping Strategies}

We defined coping strategies in line with Lazarus and Folkman (1984), according to whom coping includes drawing upon a set of cognitive and behavioral resources to manage the demands of external circumstances. To distinguish different types of coping strategies relating to children and adolescents, we adapted the classification proposed by ZimmerGembeck and Skinner (2011), who assumed a developmental perspective. We coded coping into 12 families: (1) Problem solving, which consists of strategizing, instrument action, and planning; (2) Information seeking, which involves activities like reading, observation, and asking others; (3) Helplessness, which implies confusion, cognitive interference, and cognitive exhaustion; (4) Escape, which regards behavioral avoidance, mental withdrawal, denial, and wishful thinking; (5) Self-reliance, which consists of emotion regulation, behavior regulation, emotional expressions, and emotion approach; (6) Social support, which can be given or received; (7) Delegation, which implies maladaptive help seeking, complaining, whining, and self-pity; (8) Social isolation, which includes social distancing and withdrawal from others; (9) Accommodation, which is a way to distract oneself, minimize, or accept the situation, and can involve a process of cognitive restructuring; (10) Negotiation, which involves attempts of bargaining and persuasion; (11) Submission, which is an attitude of renunciation concerning the problem, and includes rumination in terms of negative repetitive thoughts on the stressful event, rigid perseveration, and intrusive thoughts; (12) Opposition, which implies aggression, lack of cooperation, and blaming others. For each study, we report the instruments used to measure the coded coping strategies in Table 2.

\section{Maladjustment/Adjustment Measures}

Many studies explored the psychological consequences of exposure to traumatic events, emphasizing their impact on psychological maladjustment. However, some recent 


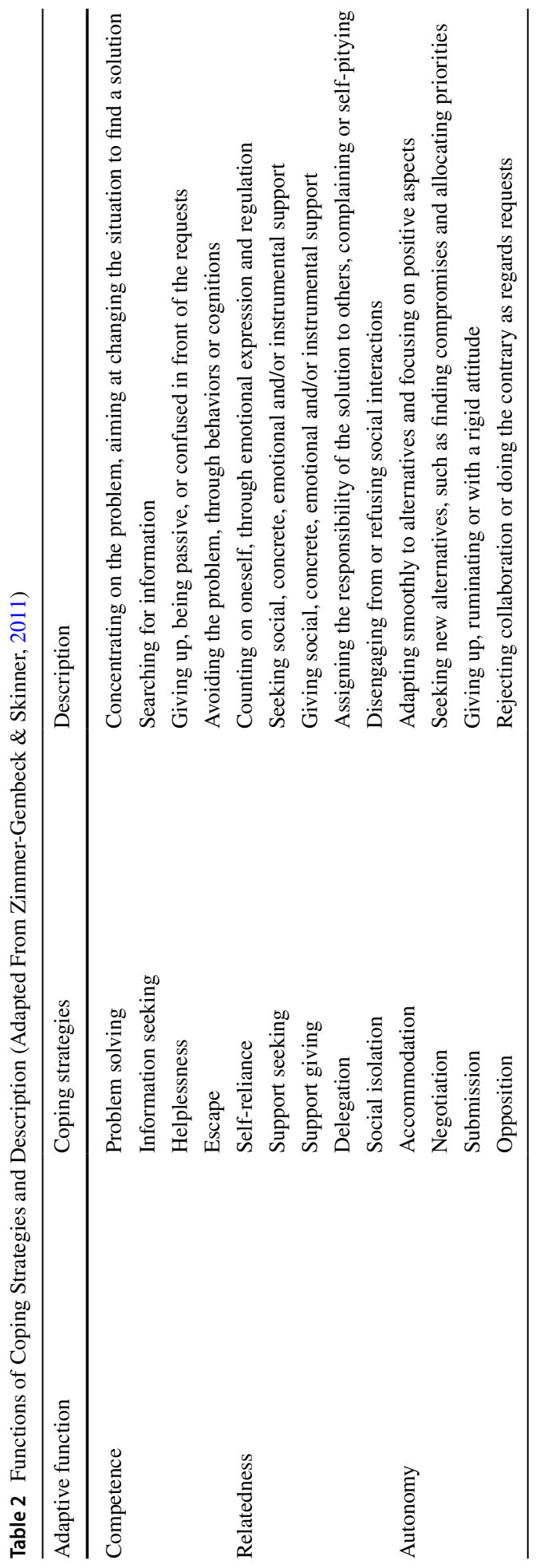


researches suggest that they can be also associated with increased resilience through psychological adjustment (Cheng et al., 2014).

We coded each study for whether it included a measure of maladjustment and/or adjustment (Table 1), taking into account the fact that the exposure to natural disasters can lead to serious negative effects for children and adolescents in both the short and long term (Fergusson \& Boden, 2014; Furr et al., 2010; Kar, 2009; Masten \& Osofsky, 2010; Neria et al., 2008; Tang et al., 2014; Wang et al., 2013; Weissbecker et al., 2008). We considered as indicators of maladjustment the traumatic consequences for mental health, such as PTSD (e.g., Russoniello et al., 2002; Wang et al., 2020), depression (e.g., Felton et al., 2013; Papadatou et al., 2012), anxiety and fear (e.g., Qin et al., 2016; Terranova et al., 2009), and psycho-social distress (e.g., Vigil \& Geary, 2008; Yang et al., 2010).

We coded adjustment considering different indicators pertaining to specific domains (i.e., cognitive, emotional, social, and motivational) or as not related to any specific domain. Indicators of cognitive functioning included, for example, cognitive performance and theory of mind abilities (Cadamuro et al., 2015). The emotional domain referred to indicators of emotional competence, such as the understanding of emotions after the exposure to a natural disaster (e.g., Raccanello et al., 2017). The social domain was operationalized, for example, in terms of understanding of oneself and others, or growth of communication and relationship skills (Bokszczanin, 2012; Yang et al., 2010). Regarding the motivational domain, the indicators pertained to perceived competence, self-efficacy, or self-concept (Kilmer \& Gil-Rivas, 2010; Wu et al., 2014; Yang et al., 2010). Concerning the general domain, some indicators of adjustment related, for example, to PTG and resilience (Cryder et al., 2006; Kilmer \& Gil-Rivas, 2010; Stratta et al., 2013).

\section{Reliability}

A first judge coded all the selected articles for coping strategies and maladjustment/adjustment measures. A second judge coded $30 \%$ of them for reliability. For coping strategies, the Cohen's $K$ was 0.98, while for maladjustment/adjustment measures it was 1 . Disagreements were resolved through discussion between judges.

\section{Data Analysis}

We carried out two meta-analyses to explore the relations between coping strategies and maladjustment on the one hand, and adjustment on the other hand. We conducted the statistical analyses using the Metafor package of R, Version 2.1 (R Core Team, 2020). We computed the effect sizes and corresponding 95\% confidence intervals (CI) for each study. We reported the effect sizes as correlations between coping strategies and maladjustment/ adjustment. According to Cohen's criteria (1988), $r$ less than I.10I are considered as very

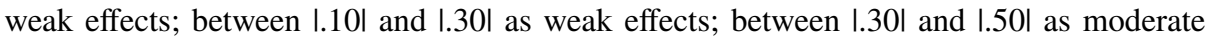
effects; and higher than $|.50|$ as large effects.

An important assumption in traditional meta-analytic approaches is that there is no dependency between effect sizes in the data set. In our data set, in many cases, we had more than one effect size extracted from the same study, thus resulting in interdependent effect sizes. In the literature, there are various suggested approaches for dealing with this interdependency (e.g., Assink \& Wibbelink, 2016; Tanner-Smith \& Tipton, 2014; Van den Noortgate \& Onghena, 2003). We chose the multilevel approach using the rma.mv function of the Metafor package. This solution allowed us to account for the dependency within the 
studies, assigning the same random effect to effect sizes with the same value of the grouping variable (that is the variable "study" in our work). However, because Van den Noortgate and Onghena (2003) suggested that, for models without moderators, the results of the multilevel approach are not substantially different from the results of the traditional random-effects approaches, we chose to run traditional random-effects meta-analyses to evaluate the main effects, the publication bias, and the presence of outliers, while we used multilevel mixed-effects meta-analyses to evaluate the role of the moderators. We performed the multilevel mixed-effects models using the restricted maximum-likelihood estimation method, in order to take into account non-independent sampling errors due to the presence of multiple effects in the studies (Borenstein, 2009). We examined the impact of each moderator on the effect size using separate mixed-effect models and, at the same time, we accounted for the dependence of effect sizes belonging to the same studies by using multilevel modelling (level $1=$ effect sizes, the variable which identified all effect sizes; level $2=$ study, the variable which identified primary studies). We also calculated intra-class correlation (ICC) to confirm that the multilevel approach was appropriate for our datasets. In multilevel analyses, ICC values higher than 0.05 support the use of a multilevel strategy (LeBreton \& Senter, 2008).

We explored the role of the following moderator variables, separately for maladjustment and adjustment:

- Types of coping strategies (problem solving, information seeking, helplessness, escape, self-reliance, social support, delegation, social isolation, accommodation, negotiation, submission, opposition);

- Age (children, adolescents);

- Type of disaster (earthquakes, floods and hurricanes, wildfires);

- Continent (America, Europe, Asia).

Only studies that had information regarding each moderator were included in the corresponding analysis. Furthermore, we analyzed the interaction with the type of coping strategies for age, type of disaster, and continent.

We evaluated heterogeneity across studies by using Cochran's heterogeneity statistic $(Q)$, in order to test the null hypothesis according to which the effect sizes of different studies are similar enough to share a common effect size (Cochran, 1954). There is heterogeneity between the effects if a significant value of $Q$ is found. We also used the $Q$ statistic to test the significance of moderators (a significant $Q$ for the comparison indicates that the difference between the combined effect sizes of the subsets of studies is significant; Borenstein, 2009; Rosenthal, 1995). To verify the level of heterogeneity, we used the $I^{2}$ statistic, which measures the proportion of total variance due to the variability between studies. Low values of the statistic (i.e., 1-49) correspond to low heterogeneity, medium values (i.e., 50-74) correspond to moderate heterogeneity, and high values (i.e., 75-100) correspond to high levels of heterogeneity. We checked for potential outliers by examining the distribution of the effect sizes (funnel plot and radial plot) and the influence of individual studies on heterogeneity ( $Q$ statistic) and on the general model (Cook's distance). To investigate potential publication biases (i.e., biases due to the publication process whereby those studies without significant results are not published), we used the trim and fill approach of Duval and Tweedie (2000). This is a non-parametric method that estimates the number of studies missing from the meta-analysis by suppressing the studies that generate patterns of asymmetry, and generating new data based on the initial sample to obtain a symmetrical 
effect size distribution. For this analysis, a funnel plot is constructed by plotting the effect size against the standard error for each study.

\section{Results}

We conducted two meta-analyses, studying the relationship between coping strategies and maladjustment in one analysis, and between coping strategies and adjustment in the other.

\section{Coping Strategies and Maladjustment}

Initially, we analyzed the correlations between coping strategies and maladjustment for the studies included in the meta-analysis. The effect sizes were in different directions for diverse coping strategies, but they seemed to be in the expected direction. The random effects model, $k=64, n=9692$, estimated a weak medium effect size, $r=0.19,95 \% \mathrm{CI}$ $[0.12,0.26], S E=0.04$. The studies were heterogeneous, $Q(63)=22,625.62, p<0.001$, and the proportion of total variance due to the variability between the studies was very high, $I^{2}=98.94 \%$. The trim and fill test was significant, suggesting the presence of a publication bias and indicating the need to add 14 effects on the right side. The new estimated effect size was higher, $r=0.28,95 \%$ CI $[0.21,0.36], S E=0.04$. Then, we evaluated the presence of potential outliers checking the distribution of the effect sizes (using the funnel plot and the radial plot) and the influence of individual studies on heterogeneity ( $Q$ statistic) and on the general model (Cook's distance). Two studies (i.e., Papadatou et al., 2012; Yang et al., 2010) had an effect size very far from the medium effect size estimated and from the confidence intervals, with $r=0.96$ and $r=0.93$, respectively. The radial plot confirmed the anomaly of these effects. Furthermore, both studies had high Cook's distance values, indicating a huge influence on the medium effect size estimated and had also a large influence on the heterogeneity measure. Consequently, we decided to exclude them and to run a third random-effects model. Again, the trim and fill test was significant, suggesting the presence of a publication bias. The test indicated the need to add 13 effects, on the right side (see Fig. 2). The effect size estimated by this model was still moderate, $r=0.25,95 \%$ CI $[0.18,0.32], S E=0.03$, although lower but more accurate than that estimated by the first random-effects model (Fig. 3). The heterogeneity of the studies was still very high, $Q(74)=3993.05, p<0.001, I^{2}=96.82 \%$. At the end of this process, we checked whether the estimated effect was really close to that obtained by the multilevel random-effects model. The effect size estimated through the multilevel model was effectively close to the effect size of the third model, $r=0.23,95 \%$ CI [0.13, 0.33], $S E=0.05$ (Van den Noortgate \& Onghena, 2003). The ICC was 0.34 , confirming the importance of using a multilevel analysis.

Then, we ran multilevel mixed-effects models to verify whether some moderator variables could explain the high heterogeneity. Only the type of coping strategies and the continent seemed to moderate the relation between maladjustment and coping strategies. However, the interaction between the type of coping strategies and the other moderators (age of participants, type of disaster, and continent) was statistically significant. The moderator analysis for the type of coping strategies, $Q_{M O D E L}(10)=333.94, p<0.001$, explained the variance in the primary effect sizes and indicated that the remaining variability across effect sizes was still heterogeneous, $Q_{\text {RESIDUAL }}(51)=654.43, p<0.001$. The analysis for the type of coping strategies also highlighted a positive statistically significant relation 


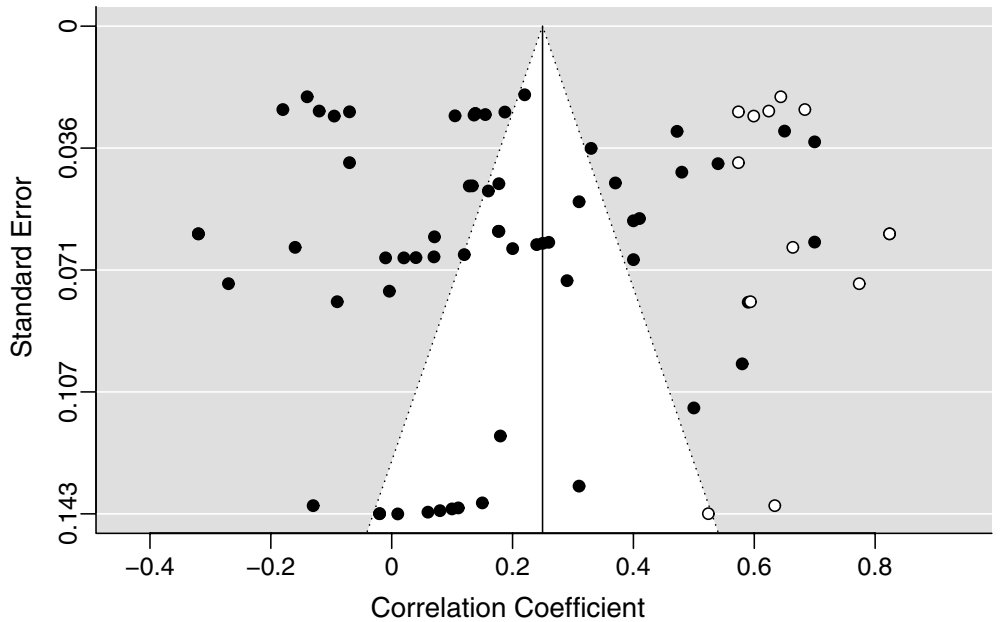

Fig. 2 Funnel Plot of Maladjustment Indicators Effect Size. For the Trim-and-Fill Analysis, we Added 13 Studies on the Right Side

between maladjustment and some coping strategies, i.e., escape, $r=0.19, p<0.001$, social isolation, $r=0.15, p=0.017$, submission, $r=0.64, p<0.001$, and opposition, $r=0.16$, $p=0.009$. The moderator analysis for continent, $Q_{M O D E L}(3)=21.39, p<0.001$, explained the variance in the primary effect sizes and indicated that the remaining variability across effect sizes was still heterogeneous, $Q_{\text {RESIDUAL }}(51)=1818.69, p<0.001$. Concerning age, we found a statistically significant interaction with coping strategies, $Q_{M O D E L(16)}=247.04$, $p<0.001$. For children there was a positive relation between self-reliance and maladjustment, $r=0.34, p<0.001$. We also found an interaction between type of coping strategies and type of disaster. In particular, there was a negative relation between maladjustment and escape for wildfires, $r=-0.20, p=0.001$; for earthquakes, the analysis highlighted a negative relation of maladjustment with problem solving, $r=-0.19, p=0.009$, self-reliance, $r=-0.29, p<0.001$, and submission, $r=-0.43, p<0.001$. Finally, the interaction between coping strategies and continent revealed that in North America problem solving, $r=0.20, p=0.007$, self-reliance, $r=0.29, p<0.001$, and submission, $r=0.43, p<0.001$, were positively associated with maladjustment. In Europe escape resulted negatively associated with maladjustment, $r=-0.42, p<0.001$.

\section{Coping Strategies and Adjustment}

Concerning adjustment, the correlations with coping strategies for the individual studies included in the meta-analysis were in different directions for diverse coping strategies, but they seemed to be in the expected direction as well. The random-effects model, $k=37$, $n=3504$, estimated a small medium effect size, $r=0.15,95 \%$ CI [0.07, 0.22], $S E=0.04$. The studies were heterogeneous, $Q(36)=1194.41, p<0.001$, and the proportion of total variance due to the variability between the studies was very high, $I^{2}=96.18 \%$. The trim and fill test was not significant, suggesting the absence of publication biases (Fig. 4). Then, again we evaluated the presence of potential outliers checking the distribution of the effect 


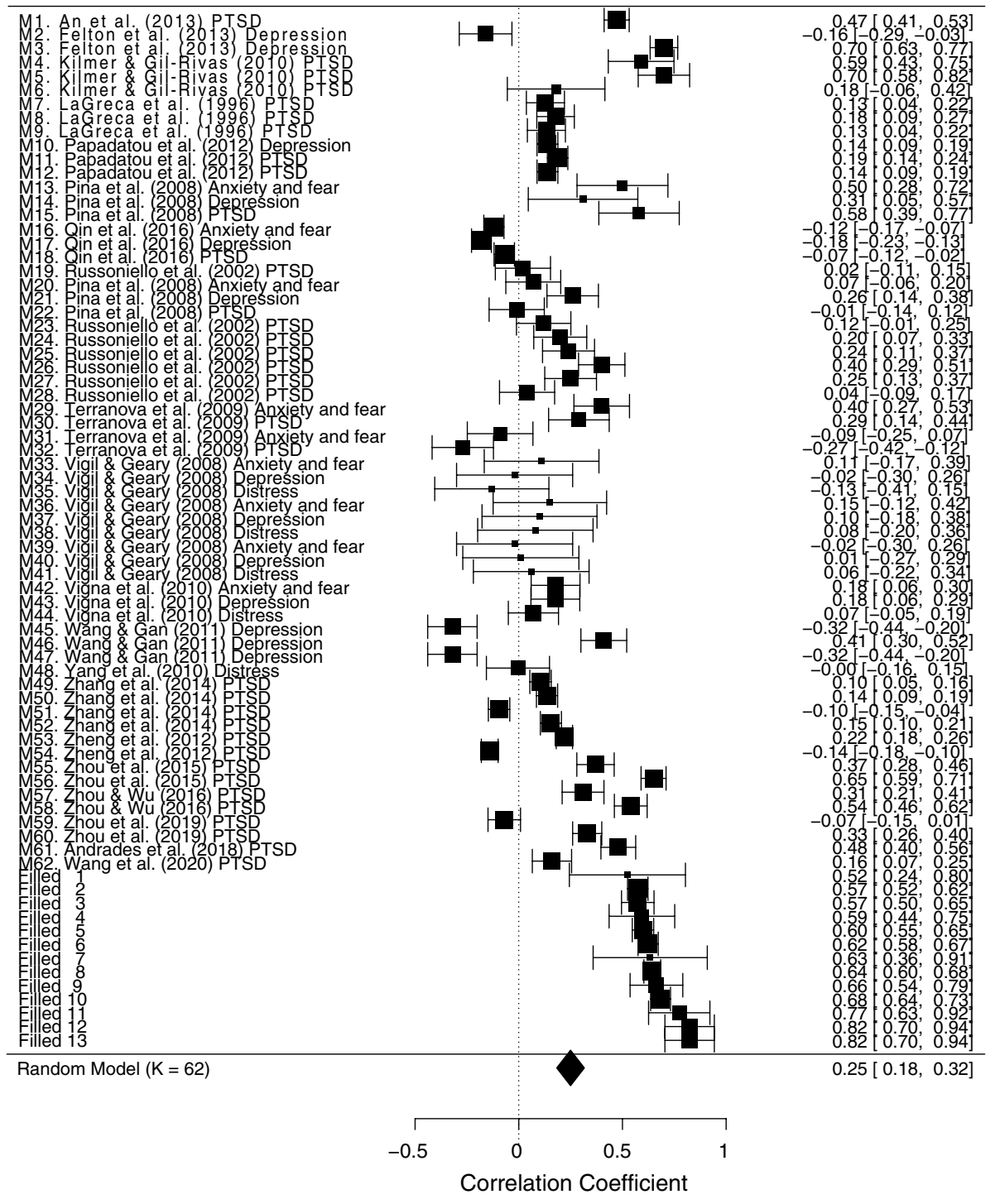

Fig. 3 Forest Plot of Maladjustment Effect Size. For Each Study There Were One or More Indicators of Maladjustment (M, see Table 1)

sizes (through the funnel plot and the radial plot) and the influence of individual studies on heterogeneity (Q statistic) and on the general model (Cook's distance). The analysis of the outliers suggested that the study by Andrades et al. (2018) had to be deleted. In this case, the effect size was very far from the medium effect size estimated and from the confidence intervals, $r=0.68$. It was characterized by a high Cook's distance value, and it had a large influence on the studies' heterogeneity. After the exclusion of this study we reran the model to calculate the new estimated effect size, i.e., $r=0.13,95 \%$ CI $[0.06,0.20], S E=0.04$. The heterogeneity of the studies was still very high, $Q(35)=779.01, p<0.001, I^{2}=95.27 \%$ 
(see the forest plot in Fig. 5). Then, we checked the presence of a publication bias through the trim and fill test, but it was again not statistically significant. We also checked whether the estimated effect was similar to that obtained by the multilevel analysis which took into account the dependence of effect sizes from the same studies. The effect size estimated with the multilevel approach was very close to that of our traditional random-effects model, $r=0.17,95 \%$ CI $[0.08,0.26], S E=0.05$ (Van den Noortgate \& Onghena, 2003). The ICC was 0.16 , confirming also for this dataset the relevance of using a multilevel analysis.

We proceeded with the moderation analysis to assess whether moderator variables could explain the high heterogeneity. Only type of coping strategies moderated the relation between coping strategies and adjustment. We also evaluated the interaction between type of coping strategies and the other potential moderators, and we found an interaction for all of them (i.e., type of disaster), except continent. The moderator analysis for type of coping strategies, $Q_{M O D E L}(5)=271.13, p<0.001$, explained the variance in the primary effect sizes but indicated that the remaining variability across effect sizes was still heterogeneous, $Q_{\text {RESIDUAL }}(30)=315.18, p<0.001$. The analysis for the type of coping strategies highlighted a positive statistically significant relation between adjustment and some coping strategies, i.e., problem solving, $r=0.31, p<0.001$, social support, $r=0.22$, $p=0.005$, and submission, $r=0.30, p<0.001$. In the evaluation of the interaction between type of coping strategies and age, even if we found a statistically significant interaction, $Q_{M O D E L}(10)=272.24, p<0.001$, no correlation was statistically significant separately for children and adolescents. The same happened for the interaction between coping strategies and type of disaster, $Q_{M O D E L}(8)=273.28, p<0.001$.

\section{Discussion}

These meta-analyses aimed at exploring the efficacy of different disaster-related coping strategies in children and adolescents. Acknowledging that the efficacy of coping depends on a variety of factors pertaining both to individuals and the context in which they find themselves, the

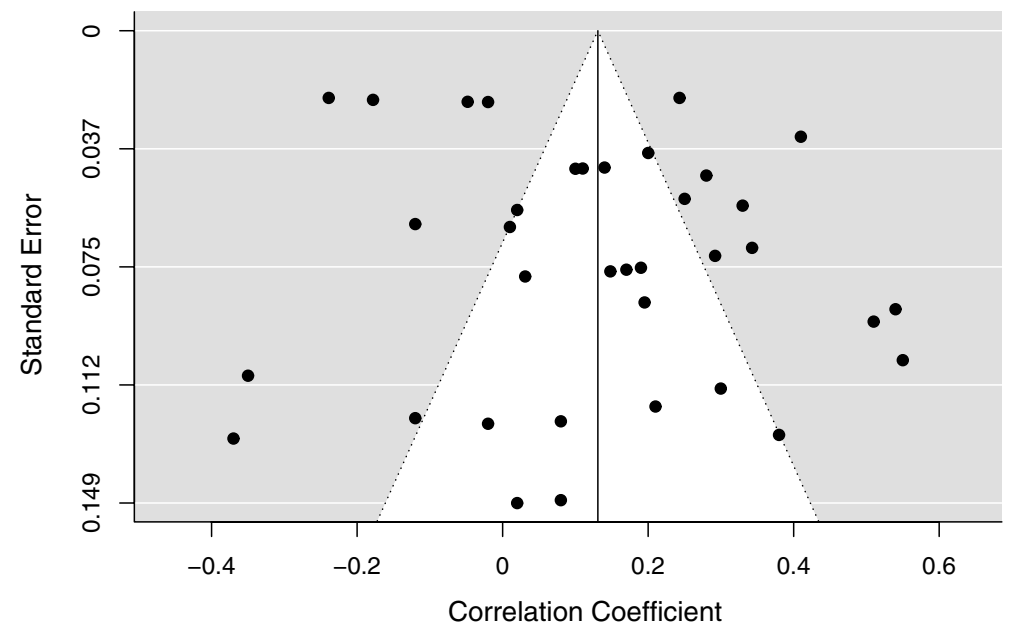

Fig. 4 Funnel Plot of Adjustment Effect Size. The Trim-and-Fill Analysis Suggested the Absence of Publication Biases 


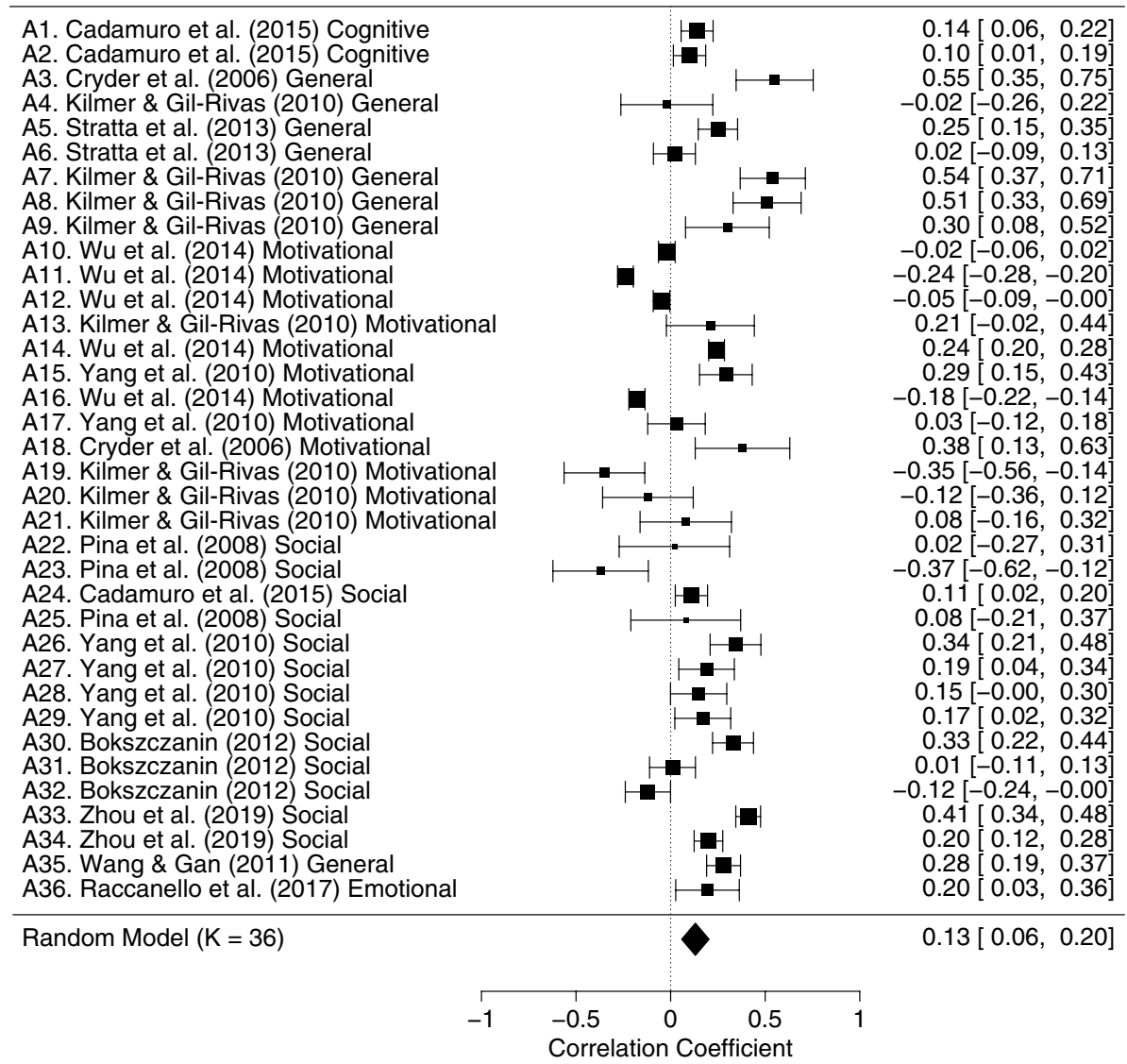

Fig. 5 Forest Plot of Adjustment Indicators Effect Size. For Each Study There Were One or More Indicators of Adjustment (A, see Table 1)

results enabled us to identify which coping strategies seem more adequate for helping children and adolescents to face a natural disaster.

The analysis of the studies on maladjustment confirmed a statistically significant and positive relation with some coping strategies, i.e., escape, social isolation, submission, and opposition, supporting Hypothesis 1. According to Zimmer-Gembeck and Skinner (2011), "maladaptive" families of coping strategies have effects on the maintenance and reinforcement of psychopathological symptoms, in particular PTSD, depression, anxiety and fear, connected to disaster exposure. These symptoms have an important role in inhibiting the activation of adaptive strategies, and predispose subjects to dysfunctional ways of coping with stressors, such as avoidance, escape, aggression, social withdrawal, etc. Helplessness was one of the two groups of coping strategies that did not show a significant relation with maladjustment. However, this strategy inhibits any action, while the other strategies involve the activation of maladaptive behaviors. The other group was delegation, which is conceptualized by Zimmer-Gembeck and Skinner (2011) as maladaptive for its focus on self-pity, complaining, or whining. However, it 
might be that delegating results in a feeling of being relieved of one's responsibilities and may then possibly play an adaptive role. Future studies should investigate this possibility.

The results show a statistically significant and positive relationship between adjustment and some coping strategies: problem solving, social support, and submission. According to previous studies (Bokszczanin, 2012; Swiatek, 2001; Zimmer-Gembeck \& Skinner, 2011), problem solving and social support have an adaptive role as coping families oriented to the activation of effective environmental resources and management of social resources involving relationships. Unexpectedly, submission was positively related to adjustment. According to Skinner et al. (2003), this strategy is considered a "maladaptive" family. It is worth noting that the studies considered in the current meta-analysis explored only the relation between submission and PTG. PTG is a complex construct, in which different factors tend to coexist, such as a greater awareness of personal strength, a change of perspective regarding one's relationships, a change in the philosophy of life in terms of greater appreciation for life and new possibilities, and spiritual growth (Tedeschi et al., 1998). For example, a recent study investigated the correlation between submission and PTG, emphasizing that discomfort in combination with reflexive processes could facilitate positive changes in the subject's functioning after exposure to trauma (Kilmer \& Gil-Rivas, 2010). Therefore, Hypothesis 2 was only partially supported.

In addition, we examined the moderating role of age, type of disaster, and continent. The results of the two meta-analyses suggested that some moderators have an effect on the relationships with coping strategies. For example, children show a more positive relation between maladjustment and self-reliance compared with adolescents. Indeed, children have fewer resources available to cope with traumatic events than adolescents because the emotional competence is necessarily related to the child's developmental growth (Compas, 1987). Furthermore, the results of the analyses revealed the moderating effect of type of disaster. We found a significant and negative relation between maladjustment and escape in the case of wildfires. In this case, using a behavioral escape strategy can be adaptive. If this strategy is activated immediately, the negative symptoms associated with the disaster could be inhibited and mitigated by the shorter duration of exposure. In line with the literature (Zimmer-Gembeck \& Skinner, 2011), children and adolescents exposed to an earthquake showed a negative relation between maladjustment and problem solving. Finally, we explored the interaction between coping strategies and continent. In North America, submission and, unexpectedly, problem solving and self-reliance strategies were positively associated with maladjustment; in Europe, escape resulted negatively associated with maladjustment. Although this result is ambiguous, it is necessary to underline the high heterogeneity of the studies, with an unequal distribution of the disasters across the three continents investigated. Future research should examine this issue. Finally, no significant moderators were found for adjustment; we could speculate that this was due to the small number of studies available for analysis.

Our study suffers from several limitations. First, the studies available were characterized by a high heterogeneity. For example, some studies focused on only maladjustment or adjustment measures, while others focused on both. It was also the case that studies included in these meta-analyses varied considerably in the definition of coping strategies, in the terminology used, and in the instruments employed to assess them. Future research could focus on these issues including, for example, studies concerning technological disasters. Second, the number of studies selected through the PRISMA was relatively small. Consequently, we could not directly investigate the differential impact of each category of maladjustment (four categories) and adjustment (five categories) on each coping strategy (12 types) because the number of studies for each intersection was quite low and the data was non-homogeneous. Third, we did not examine the effects of moderators such as gender or time from the disaster. 
These meta-analyses does help to clarify which coping strategies are the most effective in diminishing and/or avoiding traumatic consequences of natural disasters in children and adolescent victims. This knowledge can be the base from which to develop actions focused on increasing awareness about and implementation of effective strategies amongst both professionals and the public. A central issue is creating content that is relevant for children and adolescents; that deals with emotions and their regulation and provides tools that can be used, taking account of the characteristics of each type of disaster. A related issue is developing ways in which the content might be disseminated. Computer-based systems have already been developed to allow for rapid geographically dispersed delivery of content (Raccanello \& Burro, 2019).

Studies have shown that training children in coping strategies can have benefits in the event of an earthquake (Raccanello et al., 2020b). The efficacy of this kind of training, using evidence-based techniques, in advance of a disaster can be demonstrated (Flay et al., 2005). During an emergency, when timing is critical, public communication campaigns can be used to deliver information to people faced with helping children confront the looming disaster. An example was the use of the Internet to distribute a pamphlet designed to help young people cope with the emotional impact of the COVID-19 pandemic (Raccanello et al., 2020c). After a disaster, these same techniques can be paired with other psychological support methods to aid in recovery.

\section{Declarations}

Conflict of interest We have no known conflict of interest to disclose.

Open Access This article is licensed under a Creative Commons Attribution 4.0 International License, which permits use, sharing, adaptation, distribution and reproduction in any medium or format, as long as you give appropriate credit to the original author(s) and the source, provide a link to the Creative Commons licence, and indicate if changes were made. The images or other third party material in this article are included in the article's Creative Commons licence, unless indicated otherwise in a credit line to the material. If material is not included in the article's Creative Commons licence and your intended use is not permitted by statutory regulation or exceeds the permitted use, you will need to obtain permission directly from the copyright holder. To view a copy of this licence, visit http://creativecommons.org/licenses/by/4.0/.

\section{References}

Albanese, O., \& Molina, P. (2008). Lo sviluppo della comprensione delle emozioni e la sua valutazione. La standardizzazione italiana del test di comprensione delle emozioni (TEC) [The development of emotion understanding and its assessment. The Italian standardization of the test of emotion comprehension (TEC)]. Unicopli.

Amaya-Jackson, L., McCarthy, G., Newman, E., \& Cherney, M. S. (1995). Child PTSD checklist. Duke University Medical Center.

An, Y., Fu, F., Wu, X., Lin, C., \& Zhang, Y. (2013). Longitudinal relationships between neuroticism, avoidant coping, and posttraumatic stress disorder symptoms in adolescents following the 2008 Wenchuan earthquake in China. Journal of Loss and Trauma, 18(6), 556-571. https://doi.org/10.1080/15325024. 2012.719351

Andrades, M., García, F. E., Calonge, I., \& Martínez-Arias, R. (2018). Posttraumatic growth in children and adolescents exposed to the 2010 earthquake in Chile and its relationship with rumination and posttraumatic stress symptoms. Journal of Happiness Studies, 19(5), 1505-1517. https://doi.org/10.1007/ s10902-017-9885-7

Assar, M. (1971). Guide to sanitation in natural disasters. World Health Organization. https://apps.who. int/iris/handle/10665/41031 
Assink, M., \& Wibbelink, C. J. (2016). Fitting three-level meta-analytic models in R: A step-by-step tutorial. The Quantitative Methods for Psychology, 12(3), 154-174. https://doi.org/10.20982/ tqmp.12.3.p154

Benenson, J. F., Pascoe, J., \& Radmore, N. (2007). Children's altruistic behavior in the dictator game. Evolution and Human Behavior, 28(3), 168-175. https://doi.org/10.1016/j.evolhumbehav.2006.10. 003

Birleson, P. (1981). The validity of depressive disorder in childhood and the development of a self-rating scale: A research report. Journal of Child Psychology and Psychiatry, and Allied Disciplines, 22(1), 73-88. https://doi.org/10.1111/j.1469-7610.1981.tb00533.x

Birmaher, B., Khetarpal, S., Brent, D., Cully, M., Balach, L., Kaufman, J., \& Neer, S. M. (1997). The screen for child anxiety related emotional disorders (SCARED): Scale construction and psychometric characteristics. Journal of the American Academy of Child and Adolescent Psychiatry, 36(4), 545-553. https://doi.org/10.1097/00004583-199704000-00018

Bokszczanin, A. (2012). Social support provided by adolescents following a disaster and perceived social support, sense of community at school, and proactive coping. Anxiety, Stress \& Coping, 25(5), 575-592. https://doi.org/10.1080/10615806.2011.622374

Bonanno, G. A., Brewin, C. R., Kaniasty, K., \& Greca, A. M. L. (2010). Weighing the costs of disaster: Consequences, risks, and resilience in individuals, families, and communities. Psychological Science in the Public Interest, 11(1), 1-49. https://doi.org/10.1177/1529100610387086

Borenstein, M. (2009). Effect sizes for continuous data. In H. Cooper, L. V. Hedges, \& J. C. Valentine (Eds.), Handbook of research synthesis and meta-analysis (2nd ed., pp. 221-235). Russell Sage Foundation.

Brondino, M., Rocca, E., Barnaba, V., \& Vicentini, G. (2019, September 23-25). Disastri naturali e strategie di coping: Una meta-analisi su bambini e adolescenti [Natural disasters and coping strategie: A meta-analysis on children and adolescents; Poster presentation]. XXXII Congresso Nazionale AIP, Sezione di Psicologia dello Sviluppo e dell'Educazione, Naples, Italy.

Brown, R. C., Witt, A., Fegert, J. M., Keller, F., Rassenhofer, M., \& Plener, P. L. (2017). Psychosocial interventions for children and adolescents after man-made and natural disasters: A meta-analysis and systematic review. Psychological Medicine, 47(11), 1893-1905. https://doi.org/10.1017/ S0033291717000496

Cadamuro, A., Versari, A., Vezzali, L., Giovannini, D., \& Trifiletti, E. (2015). Cognitive performance in the aftermath of a natural disaster: The role of coping strategies, theory of mind and peer social support. Child \& Youth Care Forum, 44(1), 93-113. https://doi.org/10.1007/s10566-014-9272-z

Calhoun, L. G., Cann, A., Tedeschi, R. G., \& McMillan, J. (2000). A correlational test of the relationship between posttraumatic growth, religion, and cognitive processing. Journal of Traumatic Stress, 13(3), 521-527. https://doi.org/10.1023/A:1007745627077

Cann, A., Calhoun, L. G., Tedeschi, R. G., Triplett, K. N., Vishnevsky, T., \& Lindstrom, C. M. (2011). Assessing posttraumatic cognitive processes: The event related rumination inventory. Anxiety, Stress \& Coping, 24(2), 137-156. https://doi.org/10.1080/10615806.2010.529901

Capaldi, D. M., \& Rothbart, M. K. (1992). Development and validation of an early adolescent temperament measure. The Journal of Early Adolescence, 12(2), 153-173. https://doi.org/10.1177/02724 31692012002002

Carver, C. S. (1997). You want to measure coping but your protocol's too long: Consider the brief cope. International Journal of Behavioral Medicine, 4, 92. https://doi.org/10.1207/s15327558ijbm0401_6

Carver, C. S., Scheier, M. F., \& Weintraub, J. K. (1989). Assessing coping strategies: A theoretically based approach. Journal of Personality and Social Psychology, 56(2), 267-283. https://doi.org/10. 1037/0022-3514.56.2.267

Causey, D. L., \& Dubow, E. F. (1992). Development of a self-report coping measure for elementary school children. Journal of Clinical Child Psychology, 21, 47-59. https://doi.org/10.1207/s1537 4424jccp2101_8

Celebi Oncu, E., \& Metindogan Wise, A. (2010). The effects of the 1999 Turkish earthquake on young children: Analyzing traumatized children's completion of short stories. Child Development, 81(4), 1161-1175. https://doi.org/10.1111/j.1467-8624.2010.01460.x

Chen, S., Zheng, Q., Pan, J., \& Zhen, S. (2000). Preliminary development of coping style scale for middle school students. Chinese Journal of Clinical Psychology, 8(4), 211-214.

Cheng, C., Lau, H. P. B., \& Chan, M. P. S. (2014). Coping flexibility and psychological adjustment to stressful life changes: A meta-analytic review. Psychological Bulletin, 140(6), 1582-1607. https:// doi.org/10.1037/a0037913

Chorpita, B. F., Yim, L., Moffitt, C., Umemoto, L. A., \& Francis, S. E. (2000). Assessment of symptoms of DSM-IV anxiety and depression in children: A revised child anxiety and depression 
scale. Behaviour Research and Therapy, 38(8), 835-855. https://doi.org/10.1016/s0005-7967(99) 00130-8

Clarke, A. T. (2006). Coping with interpersonal stress and psychosocial health among children and adolescents: A meta-analysis. Journal of Youth and Adolescence, 35(1), 10-23. https://doi.org/10. 1007/s10964-005-9001-x

Cochran, W. (1954). Some methods for strengthening the common $\chi^{2}$ tests. Biometrics, 10(4), 417-451. https://doi.org/10.2307/3001616

Cofini, V., Carbonelli, A., Cecilia, M., Binkin, N., \& di Orio, F. (2015). Post traumatic stress disorder and coping in a sample of adult survivors of the Italian earthquake. Psychiatry Research, 229(1), 353-358. https://doi.org/10.1016/j.psychres.2015.06.041

Cohen, J. (1988). Statistical power analysis for the behavioral sciences. Routledge Academic.

Compas, B. E. (1987). Coping with stress during childhood and adolescence. Psychological Bulletin, 101(3), 393-403. https://doi.org/10.1037/0033-2909.101.3.393

Compas, B. E., Connor-Smith, J. K., Saltzman, H., Thomsen, A. H., \& Wadsworth, M. (2001). Coping with stress during childhood and adolescence: Progress, problems, and potential. Psychological Bulletin, 127(1), 87-127. https://doi.org/10.1037/0033-2909.127.1.87

Cryder, C. H., Kilmer, R. P., Tedeschi, R. G., \& Calhoun, L. G. (2006). An exploratory study of posttraumatic growth in children following a natural disaster. American Journal of Orthopsychiatry, 76(1), 65-69. https://doi.org/10.1037/0002-9432.76.1.65

Cuzzolaro, M., \& Frighi, L. (1991). Reazioni umane alle catastrofi [Human reactions to the catastrophes]. Fondazione Adriano Olivetti.

Czapinski, J. (1998). Jakość życia polaków w czasie zmiany społecznej 1991-1997 [The quality of life of Polish during the social change 1991-1997]. Instytut Studiów Społecznych, Uniwersytet Warszawski.

Deci, E. L., \& Ryan, R. M. (1985). The general causality orientations scale: Self-determination in personality. Journal of Research in Personality, 19(2), 109-134. https://doi.org/10.1016/00926566(85)90023-6

Derogatis, L. R. (1975). How to use the system distress checklist (SCL-90), psychiatric rating scale. In R. L. Derogatis (Ed.), Self-report rating scale (pp. 22-36). Hoffmann-La Roche.

Dunst, C. J., Jenkins, V., \& Trivette, C. (1984). Family support scale: Reliability and validity. Journal of Individual, Family, and Community Wellness, 1, 45-52.

Duval, S., \& Tweedie, R. (2000). Trim and fill: A simple funnel-plot-based method of testing and adjusting for publication bias in meta-analysis. Biometrics, 56(2), 455-463. https://doi.org/10.1111/j. 0006-341x.2000.00455.x

Ellis, L. K., \& Rothbart, M. K. (2001). Revision of the Early Adolescent Temperament Questionnaire [Poster presentation]. The Biennial Meeting of the Society of Research in Child Development, Minneapolis, USA.

EM-DAT. (n.d.). The international disaster database. Retrieved June 15, 2020, from https://emdat.be.

Felton, J. W., Cole, D. A., \& Martin, N. C. (2013). Effects of rumination on child and adolescent depressive reactions to a natural disaster: The 2010 Nashville flood. Journal of Abnormal Psychology, 122(1), 64-73. https://doi.org/10.1037/a0029303

Fergusson, D. M., \& Boden, J. M. (2014). The psychological impacts of major disasters. Australian and New Zealand Journal of Psychiatry, 48(7), 597-599. https://doi.org/10.1177/0004867414538677

Fields, L., \& Prinz, R. J. (1997). Coping and adjustment during childhood and adolescence. Clinical Psychology Review, 17(8), 937-976. https://doi.org/10.1016/S0272-7358(97)00033-0

Fitts, W. H. (1965). Manual for the Tennessee self concept scale. Counselor Recordings and Tests.

Flay, B. R., Biglan, A., Boruch, R. F., Castro, F. G., Gottfredson, D., Kellam, S., Mościcki, E. K., Schinke, S., Valentine, J. C., \& Ji, P. (2005). Standards of evidence: Criteria for efficacy, effectiveness and dissemination. Prevention Science, 6(3), 151-175. https://doi.org/10.1007/ s11121-005-5553-y

Flynn, B. W., \& Norwood, A. E. (2004). Defining normal psychological reactions to disaster. Psychiatric Annals, 34(8), 597-603. https://doi.org/10.3928/0048-5713-20040801-13

Foa, E. B., Johnson, K. M., Feeny, N. C., \& Treadwell, K. R. H. (2001). The child PTSD symptom scale: A preliminary examination of its psychometric properties. Journal of Clinical Child Psychology, 30(3), 376-384. https://doi.org/10.1207/S15374424JCCP3003_9

Frederick, C. J., Pynoos, R. S., \& Nader, K. O. (1992). Child post-traumatic stress reaction index. Unpublished instrument.

Furr, J. M., Comer, J. S., Edmunds, J. M., \& Kendall, P. C. (2010). Disasters and youth: A meta-analytic examination of posttraumatic stress. Journal of Consulting and Clinical Psychology, 78(6), 765780. https://doi.org/10.1037/a0021482 
Gökçen, C., Şahingöz, M., \& Annagür, B. B. (2013). Does a non-destructive earthquake cause posttraumatic stress disorder? A cross-sectional study. European Child and Adolescent Psychiatry, 22(5), 295-299. https://doi.org/10.1007/s00787-012-0348-8

Goodman, R. (1997). The Strengths and Difficulties Questionnaire: A research note. Journal of Child Psychology and Psychiatry, 38(5), 581-586. https://doi.org/10.1111/j.1469-7610.1997.tb01545.x

Green, B. L., Lindy, J. D., Grace, M. C., \& Leonard, A. C. (1992). Chronic posttraumatic stress disorder and diagnostic comorbidity in a disaster sample. Journal of Nervous and Mental Disease, 180(12), 760-766. https://doi.org/10.1097/00005053-199212000-00004

Greenberger, E., \& Chen, C. (1996). Perceived family relationships and depressed mood in early and late adolescence: A comparison of European and Asian Americans. Developmental Psychology, 32(4), 707-716. https://doi.org/10.1037/0012-1649.32.4.707

Greenglass, E. R., Schwarzer, R., Jakubiec, D., Fiksenbaum, L., \& Taubert, S. (1999). The Proactive Coping Inventory (PCI): A multidimensional research instrument [Paper presentation]. 20th International Conference of the Stress and Anxiety Research Society (STAR), Cracow, Poland.

Grych, J. H., \& Fincham, F. D. (1997). Children's adaptation to divorce. In S. A. Wolchik \& I. N. Sandler (Eds.), Handbook of children's coping (pp. 159-193). Plenum Press.

Hammill, D. D., Pearson, N. A., \& Wiederholt, J. L. (1996). Comprehensive test of nonverbal intelligence (CTONI). PRO-ED.

Happé, F. G. (1994). An advanced test of theory of mind: Understanding of story characters' thoughts and feelings by able autistic, mentally handicapped, and normal children and adults. Journal of Autism and Developmental Disorders, 24(2), 129-154. https://doi.org/10.1007/BF02172093

Harter, S. (1982). The perceived competence scale for children. Child Development, 53(1), 87-97. https://doi.org/10.2307/1129640

Hjemdal, O., Friborg, O., Stiles, T. C., Martinussen, M., \& Rosenvinge, J. H. (2006). A new scale for adolescent resilience: Grasping the central protective resources behind healthy development. Measurement and Evaluation in Counseling Development, 39(2), 84-96. https://doi.org/10.1080/ 07481756.2006 .11909791

Huang, X. T., Yu, H., Zheng, Y., Yang, J. Z., \& Wang, W. H. (2000). A preliminary research on the coping style of middle school students. Psychological Science (chinese), 23(1), 1-5.

Kar, N. (2009). Psychological impact of disasters on children: Review of assessment and interventions. World Journal of Pediatrics, 5(1), 5-11. https://doi.org/10.1007/s 12519-009-0001-x

Kilmer, R. P., \& Gil-Rivas, V. (2010). Exploring posttraumatic growth in children impacted by Hurricane Katrina: Correlates of the phenomenon and developmental considerations. Child Development, 81(4), 1211-1227. https://doi.org/10.1111/j.1467-8624.2010.01463.x

Kilmer, R. P., Gil-Rivas, V., Tedeschi, R. G., Cann, A., Calhoun, L. G., Buchanan, T., \& Taku, K. (2009). Use of the revised posttraumatic growth inventory for children. Journal of Traumatic Stress, 22(3), 248-253. https://doi.org/10.1002/jts.20410

Kovacs, M. (1992). Children's depression inventory (CDI). Multi-Health Systems Inc.

La Greca, A. M., Silverman, W. K., Vernberg, E. M., \& Prinstein, M. J. (1996). Symptoms of posttraumatic stress in children after Hurricane Andrew: A prospective study. Journal of Consulting and Clinical Psychology, 64(4), 712-723. https://doi.org/10.1037/0022-006X.64.4.712

La Greca, A. M., Silverman, W. K., Vernberg, E. M., \& Roberts, M. C. (Eds.). (2002). Helping children cope with disasters and terrorism. American Psychological Association. https://doi.org/10.1037/ 10454-000

Lai, B. S., Auslander, B. A., Fitzpatrick, S. L., \& Podkowirow, V. (2014). Disasters and depressive symptoms in children: A review. Child \& Youth Care Forum, 43(4), 489-504. https://doi.org/10. 1007/s10566-014-9249-y

Lazarus, R. S., \& Folkman, S. (1984). Stress, appraisal, and coping. Springer.

LeBreton, J. M., \& Senter, J. L. (2008). Answers to 20 questions about interrater reliability and interrater agreement. Organizational Research Methods, 11(4), 815-852. https://doi.org/10.1177/10944 28106296642

Li, Y., Li, H., Decety, J., \& Lee, K. (2013). Experiencing a natural disaster alters children's altruistic giving. Psychological Science, 24(9), 1686-1695. https://doi.org/10.1177/0956797613479975

Liu, X. C., Ma, D. D., Liu, L. Q., Zhao, G. F., Li, C. Q., Yang, J., \& Sun, L. M. (1998). Development of the post-traumatic stress disorder self-rating scale and its reliability and validity. Chinese Journal of Behavioral Medical Science, 7(5), 93-96. https://doi.org/10.1177/1524838015585313

Lonigan, C. J., Shannon, M. P., Finch, A. J., Daugherty, T. K., \& Taylor, C. M. (1991). Children's reactions to a natural disaster: Symptom severity and degree of exposure. Behavioral Research and Therapy, 13(3), 135-154. https://doi.org/10.1016/0146-6402(91)90002-R 
Masten, A. S., \& Osofsky, J. D. (2010). Disasters and their impact on child development: Introduction to the special section. Child Development, 81(4), 1029-1039. https://doi.org/10.1111/j.1467-8624.2010. 01452.x

Masten, A. S., Best, K. M., \& Garmezy, N. (1990). Resilience and development: Contributions from the study of children who overcome adversity. Development and Psychopathology, 2(4), 425-444. https:// doi.org/10.1017/S0954579400005812

McCubbin, H., Larsen, A., \& Olson, D. (1987). F-COPES: Family crisis oriented personal evaluation scales. In H. I. McCubbin \& A. I. Thompson (Eds.), Family assessment inventories for research and practice (pp. 193-207). University of Wisconsin-Madison.

Moher, D., Liberati, A., Tetzlaff, J., Altman, D. G., \& The PRISMA Group. (2009). Preferred reporting items for systematic reviews and meta-analyses: The PRISMA statement. PLoS Medicine, 6(7), e1000097. https://doi.org/10.1371/journal.pmed.1000097

Molina, P., Sala, M. N., Zappulla, C., Bonfigliuoli, C., Cavioni, V., Zanetti, M. A., Baiocco, R., Laghi, F., Pallini, S., De Stasio, S., Raccanello, D., \& Cicchetti, D. (2014). The emotion regulation checklistItalian translation. Validation of parent and teacher versions. European Journal of Developmental Psychology, 11(5), 624-634. https://doi.org/10.1080/17405629.2014.898581

Neria, Y., Nandi, A., \& Galea, S. (2008). Post-traumatic stress disorder following disasters: A systematic review. Psychological Medicine, 38(4), 467-480. https://doi.org/10.1017/S0033291707001353

Nolen-Hoeksema, S., \& Morrow, J. (1991). A prospective study of depression and posttraumatic stress symptoms after a natural disaster: The 1989 Loma Prieta earthquake. Journal of Personality and Social Psychology, 61(1), 115-121. https://doi.org/10.1037/0022-3514.61.1.115

Norris, F. H., Murphy, A. D., Kaniasty, K., Perilla, J. L., \& Ortis, D. C. (2001). Postdisaster social support in the United Stated and Mexico: Conceptual and contextual considerations. Hispanic Journal of Behavioral Sciences, 23(4), 469-497. https://doi.org/10.1177/0739986301234008

Norris, F. H., Friedman, M. J., \& Watson, P. J. (2002). 60,000 disaster victims speak: Part II. Summary and implications of the disaster mental health research. Psychiatry: Interpersonal and Biological Processes, 65(3), 240-260. https://doi.org/10.1521/psyc.65.3.240.20169

Osofsky, J. D. (Ed.). (2004). Young children and trauma: Interventions and treatment. Guilford.

Papadatou, D., Giannopoulou, I., Bitsakou, P., Bellali, T., Talias, M. A., \& Tselepi, K. (2012). Adolescents' reactions after a wildfire disaster in Greece. Journal of Traumatic Stress, 25(1), 57-63. https://doi.org/ $10.1002 /$ jts. 21656

Pina, A. A., Villalta, I. K., Ortiz, C. D., Gottschall, A. C., Costa, N. M., \& Weems, C. F. (2008). Social support, perceived discrimination, and coping as predictors of posttraumatic stress reactions in youth survivors of Hurricane Katrina. Journal of Clinical Child and Adolescent Psychology, 37(3), 564-574. https://doi.org/10.1080/15374410802148228

Pfefferbaum, B., Nitiéma, P., \& Newman, E. (2019). A meta-analysis of intervention effects on depression and/or anxiety in youth exposed to political violence or natural disasters. Child \& Youth Care Forum, 48, 449-477. https://doi.org/10.1007/s10566-019-09494-9

Prati, G., \& Pietrantoni, L. (2009). Optimism, social support, and coping strategies as factors contributing to posttraumatic growth: A meta-analysis. Journal of Loss and Trauma, 14(5), 364-388. https://doi.org/ $10.1080 / 15325020902724271$

Program for Prevention Research. (1999). Children's coping strategies checklist and the how I coped under pressure scale. Arizona State University.

Qin, Y., Zhou, Y., Fan, F., Chen, S., Huang, R., Cai, R., \& Peng, T. (2016). Developmental trajectories and predictors of prosocial behavior among adolescents exposed to the 2008 Wenchuan earthquake. Journal of Traumatic Stress, 29(1), 80-87. https://doi.org/10.1002/jts.22064

$\mathrm{R}$ Core Team. (2020). R: A language and environment for statistical computing. The R Foundation for Statistical Computing. Retrieved on February, 2020, from http://www.R-project.org/

Raccanello, D., Barnaba, V., Rocca, E., Vicentini, G., Hall, R., \& Burro, R. (2021). Adults' expectations on children's earthquake-related emotions and coping strategies. Psychology, Health \& Medicine, 26(5), 571-583. https://doi.org/10.1080/13548506.2020.1800057

Raccanello, D., \& Burro, R. (2019). Metodo per l'allenamento della prevenzione ad un disastro, nonché sistema computerizzato ed un programma eseguibile al calcolatore per l'implementazione di tale metodo (brevetto italiano n. 102019000008295) [Method for disaster prevention training, as well as a computerized system and a computer executable program for the implementation of this method]. Ufficio Italiano Brevetti e Marchi. https://it.espacenet.com/publicationDetails/biblio?CC=IT\&NR= $201900008295 \mathrm{~A} 1 \& \mathrm{KC}=\mathrm{A} 1 \& \mathrm{FT}=\mathrm{D} \& \mathrm{ND}=5 \&$ date $=20201206 \& \mathrm{DB}=\&$ locale $=$ it_IT

Raccanello, D., Burro, R., \& Hall, R. (2017). Children's emotional experience two years after an earthquake: An exploration of knowledge of earthquakes and associated emotions. PLoS ONE, 12(12), e0189633. https://doi.org/10.1371/journal.pone.018963 
Raccanello, D., Rocca, E., \& Brondino, M. (2019a). Disaster-related coping strategies: A meta-analysis on children [Poster presentation]. 19th European Congress of Developmental Psychology, Athens, Greece.

Raccanello, D., Vicentini, G., Brondino, M., \& Burro, R. (2020a). Technology-based trainings on emotions: A web application on earthquake-related emotional prevention with children. Advances in Intelligent and Soft Computing, 1007, 53-61. https://doi.org/10.1007/978-3-030-23990-9

Raccanello, D., Vicentini, G., \& Burro, R. (2019b). Children's psychological representation of earthquakes: Analysis of written definitions and Rasch scaling. Geosciences, 9(5), 208. https://doi.org/10.3390/ geosciences 9050208

Raccanello, D., Vicentini, G., Florit, E., \& Burro, R. (2020b). Factors promoting learning with a web application on earthquake-related emotional preparedness in primary school. Frontiers in Psychology, 11, 621. https://doi.org/10.3389/fpsyg.2020.00621

Raccanello, D., Vicentini, G., Rocca, E., Barnaba, V., Hall, R., \& Burro, R. (2020c). Development and early implementation of a public communication campaign to help adults to support children and adolescents to cope with coronavirus-related emotions: A community case study. Frontiers in Psychology, 11, 2184. https://doi.org/10.3389/fpsyg.2020.02184

Radloff, L. S. (1977). The CES-D scale: A self-report depression scale for research in the general population. Applied Psychological Measurement, 1(3), 385-401. https://doi.org/10.1177/014662167700100 306

Raven, J. (1981). Manual for Raven's progressive matrices and mill hill vocabulary scales. Oxford Psychology Press.

Reynolds, C. R., \& Richmond, B. O. (1978). What I think and feel: A revised measure of children's manifest anxiety. Journal of Abnormal Child Psychology, 6(2), 271-280. https://doi.org/10.1007/BF00919131

Reynolds, C. R., \& Kamphaus, R. W. (2004). Behavior assessment system for children. American Guidance Service.

Rosenthal, R. (1995). Writing meta-analytic reviews. Psychological Bulletin, 118(2), 183-192. https://doi. org/10.1037/0033-2909.118.2.183

Russoniello, C. V., Skalko, T. K., O’Brien, K., McGhee, S. A., Bingham-Alexander, D., \& Beatley, J. (2002). Childhood posttraumatic stress disorder and efforts to cope after Hurricane Floyd. Behavioral Medicine, 28(2), 61-71. https://doi.org/10.1080/08964280209596399

Rutter, M. (1996). Transitions and turning points in developmental psychopathology: As applied to the age span between childhood and mid-adulthood. International Journal of Behavioral Development, 19(3), 603-626. https://doi.org/10.1177/016502549601900309

Schaefer, J. A., \& Moos, R. H. (1992). Life crisis and personal growth. In B. N. Carpenter (Ed.), Personal coping: Theory, research, and application (pp. 149-170). CT Praeger.

Schwarzer, R., \& Jerusalem, M. (1995). Generalized self-efficacy scale. In Weinman, J., Wright, S., \& Johnston, M. (Eds.), Measures in health psychology: A user's portfolio. Causal and control beliefs (pp. 35-37). NFER-Nelson.

Silva, M. A. (2017). PCL-C. In Kreutzer, J., DeLuca, J., \& Caplan, B. (Eds.), Encyclopedia of clinical neuropsychology. Springer. https://doi.org/10.1007/978-3-319-56782-2_9235-1

Silverman, W. K., \& La Greca, A. M. (2002). Children experiencing disasters: Definitions, reactions, and predictors of outcomes. In A. M. La Greca, W. K. Silverman, E. M. Vernberg, \& M. C. Roberts (Eds.), Helping children cope with disasters and terrorism (pp. 11-33). American Psychological Association.

Skinner, E. A., Edge, K., Altman, J., \& Sherwood, H. (2003). Searching for the structure of coping: A review and critique of category systems for classifying ways of coping. Psychological Bulletin, 129(2), 216-269. https://doi.org/10.1037/0033-2909.129.2.216

Smith, P., Perrin, S., Dyregrov, A., \& Yule, W. (2003). Principal components analysis of the impact of event scale with children in war. Personality and Individual Differences, 34(2), 315-322. https://doi.org/10. 1016/S0191-8869(02)00047-8

Spirito, A., Stark, L., \& Williams, C. (1988). Development of a brief coping checklist for use with pediatric populations. Journal of Pediatric Psychology, 13(4), 555-574. https://doi.org/10.1093/jpepsy/13.4. 555

Steinberg, A. M., Brymer, M. J., Decker, K. B., \& Pynoos, R. S. (2004). The University of California at Los Angeles post-traumatic stress disorder reaction index. Current Psychiatry Reports, 6(2), 96-100. https://doi.org/10.1007/s11920-004-0048-2

Stratta, P., Capanna, C., Patriarca, S., de Cataldo, S., Bonanni, R. L., Riccardi, I., \& Rossi, A. (2013). Resilience in adolescence: Gender differences two years after the earthquake of L'Aquila. Personality and Individual Differences, 54(3), 327-331. https://doi.org/10.1016/j.jad.2012.08.048 
Sullivan, K., Zaitchik, D., \& Tager-Flusberg, H. (1994). Preschoolers can attribute second order beliefs. Developmental Psychology, 30(3), 395-402. https://doi.org/10.1037/0012-1649.30.3.395

Swiatek, M. A. (2001). Social coping among gifted high school students and its relationship to selfconcept. Journal of Youth and Adolescence, 30, 19-39. https://doi.org/10.1023/A:1005268704144

Tanner-Smith, E. E., \& Tipton, E. (2014). Robust variance estimation with dependent effect sizes: Practical considerations including a software tutorial in Stata and SPSS. Research Synthesis Methods, 5(1), 13-30. https://doi.org/10.1002/jrsm.109

Tang, B., Liu, X., Liu, Y., Xue, C., \& Zhang, L. (2014). A meta-analysis of risk factors for depression in adults and children after natural disasters. BMC Public Health, 14(1), 623.

Tedeschi, R. G., \& Calhoun, L. G. (1996). The posttraumatic growth inventory: Measuring the positive legacy of trauma. Journal of Traumatic Stress, 9(3), 455-471. https://doi.org/10.1007/BF021 03658

Tedeschi, R. G., Park, C. L., \& Calhoun, L. G. (1998). Posttraumatic growth: Positive changes in the aftermath of crisis. Routledge.

Terranova, A. M., Boxer, P., \& Morris, A. S. (2009). Factors influencing the course of posttraumatic stress following a natural disaster: Children's reactions to Hurricane Katrina. Journal of Applied Developmental Psychology, 30(3), 344-355. https://doi.org/10.1016/j.appdev.2008.12.017

Van den Noortgate, W., \& Onghena, P. (2003). Multilevel meta-analysis: A comparison with traditional meta-analytical procedures. Educational and Psychological Measurement, 63(5), 765-790. https:// doi.org/10.1177/0013164402251027

Vezzali, L., Drury, J., Versari, A., \& Cadamuro, A. (2016). Sharing distress increases helping and contact intentions via social identification and inclusion of the other in the self: Children's prosocial behaviour after an earthquake. Group Processes \& Intergroup Relations, 19(3), 314-327. https:// doi.org/10.1177/1368430215590492

Vicentini, G., Brondino, M., Burro, R., \& Raccanello, D. (2020). HEMOT®, Helmet for EMOTions: A web application for children on earthquake-related emotional prevention. Advances in Intelligent Systems and Computing, 1241, 10-19. https://doi.org/10.1007/978-3-030-52538-5_2

Vigil, J. M., \& Geary, D. C. (2008). A preliminary investigation of family coping styles and psychological well-being among adolescent survivors of Hurricane Katrina. Journal of Family Psychology, 22(1), 176-180. https://doi.org/10.1037/0893-3200.22.1.176

Vigna, J. F., Hernandez, B. C., Kelley, M. L., \& Gresham, F. M. (2010). Coping behavior in hurricaneaffected African American youth: Psychometric properties of the Kidcope. Journal of Black Psychology, 36(1), 98-121. https://doi.org/10.1177/0095798408329948

Wang, C. W., Chan, C. L., \& Ho, R. T. (2013). Prevalence and trajectory of psychopathology among child and adolescent survivors of disasters: A systematic review of epidemiological studies across 1987-2011. Social Psychiatry and Psychiatric Epidemiology, 48(11), 1697-1720. https://doi.org/ 10.1007/s00127-013-0731-X

Wang, Z., \& Gan, Y. (2011). Coping mediates between social support, neuroticism, and depression after earthquake and examination stress among adolescents. Anxiety, Stress, \& Coping, 24(3), 343-358. https://doi.org/10.1080/10615806.2010.515026

Wang, W., Wu, X., \& Lan, X. (2020). Rumination mediates the relationships of fear and guilt to posttraumatic stress disorder and posttraumatic growth among adolescents after the Ya'an earthquake. European Journal of Psychotraumatology, 11(1), 1704993. https://doi.org/10.1080/20008198. 2019.1704993

Weathers, F. W. (2013). The PTSD checklist for DSM-5 (PCL-5): Development and initial psychometric analysis [Poster presentation]. The 29th annual meeting of the International Society for Traumatic Stress Studies, Philadelphia, USA.

Weems, C. F. (2015). Biological correlates of child and adolescent responses to disaster exposure: A bioecological model. Current Psychiatry Reports, 17, 51. https://doi.org/10.1007/s11920-015-0588-7

Weems, C. F., \& Graham, R. A. (2014). Resilience and trajectories of posttraumatic stress among youth exposed to disaster. Journal of Child and Adolescent Psychopharmacology, 24(1), 2-8. https://doi. org/10.1089/cap.2013.0042

Weems, C. F., Russell, J. D., Graham, R. A., Neill, E. L., \& Banks, D. M. (2015). Developmental differences in the linkages between anxiety control beliefs and post-traumatic stress in youth. Depression \& Anxiety, 32(5), 356-363. https://doi.org/10.1002/da.22319

Weiss, D., \& Marmar, C. (1997). The impact of event scale revised. In J. Wilson \& T. Keane (Eds.), Assessing psychological trauma and PTSD (pp. 399-411). Guilford Press.

Weissbecker, I., Sephton, S., \& Simpson, D. (2008). Psychological and physiological correlates of stress in children with exposure to disaster: A review of current research. Children, Youth and Environments, 18(1), 30-70. 
Weyer, M., \& Sandler, I. N. (1998). Stress and coping as predictors of children's divorce-related ruminations. Journal of Clinical Child Psychology, 27(1), 78-86. https://doi.org/10.1207/s15374424jccp27 01_9

World Health Organization. (n.d.). Environmental health in emergencies. Natural events. Retrieved June 15, 2020, from https://www.who.int/environmental_health_emergencies/natural_events/en/\#: :text= Every\%20year\%20natural\%20disasters\%20kill,wildfires $\% 2$ C $\% 20$ heat $\% 20$ waves $\% 20$ and $\% 20$ droughts.

Wu, D., Jiang, X., Ho, K. W., Duan, L., \& Zhang, W. (2014). Factors associated with self-concept in adolescent survivors of an 8.0-magnitude earthquake in China. Nursing Research, 63(4), 278-288. https:// doi.org/10.1097/NNR.0000000000000045

Xiao, S., \& Yang, D. (1987). The influence of social support to psychological health. Chinese Mental Health Journal, 1, 184-187.

Xiao, J., \& Xu, X. (1996). Study on the validity and reliability of "COPE". Chinese Mental Health Journal, $10,164-168$.

Xie, Y. N. (1998). Preliminary study to the reliability and validity of the simple coping style scale. Chinese Journal of Clinical Psychology, 6, 114-115.

Yang, J., Yang, Y., Liu, X., Tian, J., Zhu, X., \& Miao, D. (2010). Self-efficacy, social support, and coping strategies of adolescent earthquake survivors in China. Social Behavior and Personality, 38(9), 1219-1228. https://doi.org/10.2224/sbp.2010.38.9.1219

Zhang, W., Liu, H., Jiang, X., Wu, D., \& Tian, Y. (2014). A longitudinal study of posttraumatic stress disorder symptoms and its relationship with coping skill and locus of control in adolescents after an earthquake in China. PLoS ONE, 9(2), e88263. https://doi.org/10.1371/journal.pone.0088263

Zheng, Y., Fan, F., Liu, X., \& Mo, L. (2012). Life events, coping, and posttraumatic stress symptoms among Chinese adolescents exposed to 2008 Wenchuan earthquake, China. PLoS ONE, 7(1), e29404. https:// doi.org/10.1371/journal.pone.0029404

Zhou, X., Wu, X., Fu, F., \& An, Y. (2015). Core belief challenge and rumination as predictors of PTSD and PTG among adolescent survivors of the Wenchuan earthquake. Psychological Trauma: Theory, Research, Practice, and Policy, 7(4), 391-397. https://doi.org/10.1037/tra0000031

Zhou, X., Wu, X., An, Y., \& Chen, J. (2014). The roles of rumination and social support in the associations between core belief challenge and posttraumatic growth among adolescent survivors after the Wenchuan earthquake. Acta Psychologica Sinica, 46(10), 1509-1520. https://doi.org/10.3724/SP.J.1041. 2014.01509

Zhou, X., \& Wu, X. (2016). The relationship between rumination, posttraumatic stress disorder, and posttraumatic growth among Chinese adolescents after earthquake: A longitudinal study. Journal of Affective Disorders, 193, 242-248. https://doi.org/10.1016/j.jad.2015.12.076

Zhou, X., Zhen, R., \& Wu, X. (2019). Shared and unique mechanisms underlying the association of trauma exposure with posttraumatic stress symptoms and growth among adolescents following the Jiuzhaigou earthquake. Psychological Trauma: Theory, Research, Practice, and Policy. https://doi.org/10. $1037 / \mathrm{tra0000526}$

Zimmer-Gembeck, M. J., \& Skinner, E. A. (2011). The development of coping across childhood and adolescence: An integrative review and critique research. International Journal of Behavioral Development, 35(1), 1-17. https://doi.org/10.1177/0165025410384923

Zung, W. W., Richards, C. B., \& Short, M. J. (1965). Self-rating depression scale in an outpatient clinic. Further validation of the SDS. Archives of General Psychiatry, 13(6), 508-515. https://doi.org/10. 1001/archpsyc. 1965.01730060026004

Publisher's Note Springer Nature remains neutral with regard to jurisdictional claims in published maps and institutional affiliations.

\section{Authors and Affiliations}

\section{Daniela Raccanello ${ }^{1}$ (D) Emmanuela Rocca ${ }^{1}$ E $\cdot$ Veronica Barnaba ${ }^{1}$ (D) . Giada Vicentini $^{1}$ D $\cdot$ Rob Hall ${ }^{2} \cdot$ Margherita Brondino $^{1}$}

1 Department of Human Sciences, University of Verona, Lungadige Porta Vittoria 17, 37129 Verona, Italy

2 Macquarie University and Environmetrics, Sydney, Australia 